Research paper

\title{
Construction of a series of rare earth metal-organic frameworks supported by thiophenedicarboxylate linker: Synthesis, characterization, crystal structures and near-infrared/visible luminescence
}

\author{
Lippy F. Marques ${ }^{\mathrm{a}, *}$, Hudson P. Santos ${ }^{\mathrm{a}}$, Charlane C. Correa ${ }^{\mathrm{b}}$, Jackson A.L.C. Resende ${ }^{\mathrm{c}}$, Robson R. da Silva ${ }^{\mathrm{d}}$, \\ Sidney J.L. Ribeiro ${ }^{\mathrm{d}}$, Flávia C. Machado ${ }^{\mathrm{b}}$ \\ ${ }^{a}$ Grupo de Materiais Inorgânicos Multifuncionais (GMIM), Instituto de Química, Universidade do Estado do Rio de Janeiro, Rio de Janeiro 20550-013, Brazil \\ ${ }^{\mathrm{b}}$ Grupo de Química Inorgânica Supramolecular (GQUIS), Departamento de Química-ICE, Universidade Federal de Juiz de Fora, Juiz de Fora, MG 36036-330, Brazil \\ ${ }^{\mathrm{C}}$ Laboratório de difração de raios X (LDRX), Departamento de Química Inorgânica, Universidade Federal Fluminense, Niterói, RJ 24020-141, Brazil \\ ${ }^{\mathrm{d}}$ Instituto de Química, Universidade Estadual Paulista Júlio de Mesquita Filho, UNESP, Araraquara, SP 14801-970, Brazil
}

\section{A R T I C L E I N F O}

Article history:

Received 23 May 2016

Accepted 1 July 2016

Available online 2 July 2016

\section{Keywords:}

Metal-organic frameworks

Photoluminescence

25-Thiophenedicarboxylic acid

Lanthanides

\begin{abstract}
A B S T R A C T
Six novel rare earth metal organic-frameworks with the general formula $\left\{\left[R E_{2}(2,5-t d c)_{3}(d m s o)_{2}\right] \cdot \mathrm{H}_{2} \mathrm{O}\right\}_{n}$ $\left(R E=Y^{I I I}, P r^{I I I}, N d^{I I I}, S m^{I I I}, E r^{I I I}\right.$ and $\mathrm{Tm}^{I I I} ; 2,5-t d c^{2-}=2,5$-thiophenedicarboxylate anion; dmso = dimethylsulfoxide) were synthesized and their complete characterization, including single crystal X-ray diffraction, FTIR spectroscopy and thermal analysis (TG/DTA) are reported. Structure analysis reveals that RE ${ }^{\text {III }}$ ions show distorted capped trigonal - prismatic geometry. The 2,5-tdc ${ }^{2-}$ ligands connect four RE ${ }^{\text {III }}$ centers, adopting $\left(\kappa^{1}-\kappa^{1}\right)-\left(\kappa^{1}-\kappa^{1}\right)-\mu_{4}$ coordination mode, generating an interesting 3D network with potential application for gas adsorption. Photophysical properties were studied using excitation/emission spectra and the photoluminescence data show the near infrared (NIR) and visible (Vis) emission with the characteristic transitions: ${ }^{1} \mathrm{D}_{2} \rightarrow{ }^{3} \mathrm{~F}_{2}$ for $\mathrm{Pr}^{\mathrm{III}},{ }^{4} \mathrm{~F}_{3 / 2} \rightarrow{ }^{4} \mathrm{I}_{\mathrm{J}}(J=9 / 2,11 / 2$ and $13 / 2)$ for $\mathrm{Nd}^{\mathrm{III}},{ }^{4} \mathrm{G}_{5 / 2} \rightarrow{ }^{6} \mathrm{H}_{\mathrm{J}} \mathrm{J}=5 / 2,7 / 2,9 / 2$ and $11 / 2$ ) for $\mathrm{Sm}^{\mathrm{III}}$ and ${ }^{4} \mathrm{I}_{13 / 2} \rightarrow{ }^{4} \mathrm{I}_{15 / 2}$ for $\mathrm{Er}^{\mathrm{III}}$. This study indicates that $2,5-\mathrm{tdc}^{2-}$ ligand is able to act as a sensitizer for emission in NIR and Vis region in these ions.
\end{abstract}

(c) 2016 Elsevier B.V. All rights reserved.

\section{Introduction}

Metal-organic frameworks (MOFs) are extended crystalline structures wherein metal cations or clusters of cations are connected by polytopic organic linkers to form one-, two-, or threedimensional structural arrangement. Such compounds have attracted great attention from both academia and industry because of their potential applications in a wide variety of fields such as: magnetism [1], catalysis [2], gas storage [3] and molecular separation [4]. In this context, the use of rare earth ions in the construction of metal-organic frameworks results in a specific class of compounds called Rare Earth Metal-Organic Frameworks (REMOFs) with unique optical and magnetic properties. Different from other metal ions and molecular species, the rare earth ions have a narrow absorbance and emission bands with high quantum yields when excited via antenna effect [5,6]. This process consists in the use of suitable chromophores, employed as antennas (or sensitizers)

\footnotetext{
* Corresponding author.

E-mail address: lippymarquesuerj@gmail.com (L.F. Marques).
}

with the capability of transferring energy indirectly to rare earth ions as for example the carboxylate ligands. This intramolecular energy transfer is crucial once that some rare earth ions systems with direct absorption in the $f$ excited states is very inefficient because the $4 f-4 f$ transitions are parity forbidden, resulting in very low absorption coefficients. Some REMOFs, specially containing lanthanide $\mathrm{Eu}^{\mathrm{III}}$ and $\mathrm{Tb}^{\mathrm{III}}$ ions, usually exhibit intense luminescence and are potentially applicable for sensors, lightning and optical devices [7]. Recently, interest towards the compounds containing $\mathrm{Er}^{\mathrm{III}}, \mathrm{Pr}^{\mathrm{III}}$ and $\mathrm{Nd}^{\mathrm{III}}$ ions, which emit in the near infrared (NIR) region, has increased. This is mainly due the potential applications in telecommunication network as optical signal amplifier, and in biological and medical systems as luminescent probes [8]. Taking advantage of the high affinity of rare earth ions for oxygen, a number of REMOFs with various dimensionality and topologies have been synthesized from multicarboxylate ligands [9,10]. In this paper, we chose the rigid ligand 2,5-thiophenedicarboxylic acid $\left(2,5-\mathrm{H}_{2} \mathrm{tdc}\right)$ to promote the formation of extended REMOFs structures, which exhibit high connectivity, stabilize bridges among several metal centers [11-13], adopting several coordination 
modes, and producing multidimensional networks, including 2D and 3D structures. Given the important potential applications, we described the synthesis, characterization, structures and luminescence properties of rare earth metal-organic frameworks of general formula $\left\{\left[R E_{2}(2,5-t d c)_{3}(d m s o)_{2}\right] \cdot \mathrm{H}_{2} \mathrm{O}\right\}_{n}\left(\mathrm{RE}=\mathrm{Y}^{\mathrm{III}}, \mathrm{Pr}^{\mathrm{III}}, \mathrm{Nd}^{\mathrm{III}}, \mathrm{Sm}{ }^{\mathrm{III}}\right.$, $\mathrm{Er}^{\mathrm{III}}$ and $\mathrm{Tm}^{\mathrm{III}} ; 2,5-\mathrm{tdc}^{2-}=2,5$-thiophenedicarboxylate anion; dmso $=$ dimethylsulfoxide).

\section{Experimental}

\subsection{Materials and physical measurements}

Elemental analyses for $\mathrm{C}$ and $\mathrm{H}$ were carried out using a PerkinElmer 2400CHN analyzer. X-ray diffraction patterns (PXRD) of the single crystals were recorded on a Rigaku RINT2000 diffractometer using $\mathrm{Cu} \mathrm{K} \alpha$ radiation ( $30 \mathrm{kV}$ and $15 \mathrm{~mA}$ ) from $5^{\circ}$ to $70^{\circ}$ and $0.02^{\circ}$ of pass time. FTIR spectra were recorded with a Bomem Michelson 102 FTIR spectrophotometer using $\mathrm{KBr}$ pellets in the wavenumber range of $4000-400 \mathrm{~cm}^{-1}$ with an average of 128 scans and $4 \mathrm{~cm}^{-1}$ of spectral resolution. Thermal analysis (TGA/DTA) was obtained on a Shimadzu TG-60 equipment with 6-10 mg sample being heated at $10^{\circ} \mathrm{C} / \mathrm{min}$ from room temperature to $800^{\circ} \mathrm{C}$ in a dynamic nitrogen atmosphere (flow rate $=100 \mathrm{~mL} / \mathrm{min}$ ). The images of scanning electron microscopy were obtained using a Shimadzu SS - 50 with tungsten filament working at $2.0 \mathrm{kV}$, work distance 17 and probe 4.0. Diffuse reflection (DR) spectra were acquired with a Cary 500 spectrophotometer from 200 to $1500 \mathrm{~nm}$ with spectral resolution of $1 \mathrm{~nm}$. The luminescence excitation and emission spectra were obtained with a Jobin-Yvon Model Fluorolog FL3-22 spectrophotometer equipped with a R928 Hamamatsu photomultiplier and $450 \mathrm{~W}$ xenon lamp as excitation source and the spectra were corrected with respect to the Xe lamp intensity and spectrometer response.

\subsection{Synthesis of $\left\{\left[R E_{2}(2,5-t d c)_{3}(d m s o)_{2}\right] \cdot H_{2} O\right\}_{n}$}

\subsubsection{Synthesis of $\left\{\left[\mathrm{Y}_{2}(2,5-\mathrm{tdc})_{3}(\mathrm{dmso})_{2}\right] \cdot \mathrm{H}_{2} \mathrm{O}\right\}_{n}(\mathbf{1})$}

Compound (1) was synthesized using a two layered solution in a tube of $1.5 \mathrm{~cm}$ inner diameter and $18 \mathrm{~cm}$ height. The bottom layer was $10 \mathrm{~mL}$ of $\mathrm{N}, \mathrm{N}^{\prime}$-dimethylformamide and dimethylsulfoxide mixture (1:1) containing $0.24 \mathrm{mmol}(42 \mathrm{mg})$ of 2,5-thiophenedicarboxylic acid. The upper one was $5 \mathrm{~mL}$ of an ethanolic solution containing $0.16 \mathrm{mmol}\left(50 \mathrm{mg}\right.$ ) of $\mathrm{YCl}_{3} \cdot 6 \mathrm{H}_{2} \mathrm{O}$. The resulting solution was allowed to stand and after five weeks, colorless block crystals suitable for single crystal $\mathrm{X}$-ray diffraction analysis were obtained. Yield: 57\%. Anal. Calc. for $\mathrm{Y}_{2} \mathrm{C}_{22} \mathrm{H}_{20} \mathrm{O}_{15} \mathrm{~S}_{5}$ : C, 30.6; $\mathrm{H}, 2.34 \%$; Found: C, 31.0; H, 2.33\%.

\subsubsection{Synthesis of compound $\left\{\left[\operatorname{Pr}_{2}(2,5-t d c)_{3}(d m s o)_{2}\right] \cdot \mathrm{H}_{2} \mathrm{O}\right\}_{n}$ (2)}

Compound (2) was obtained by applying the same synthetic procedure as described for (1), except that $\mathrm{PrCl}_{3} \cdot 6 \mathrm{H}_{2} \mathrm{O}(50 \mathrm{mg}$, $0.14 \mathrm{mmol}$ ) was used instead of $\mathrm{YCl}_{3} \cdot 6 \mathrm{H}_{2} \mathrm{O}$. The resulting solution was allowed to stand and after five weeks, light green block crystals were formed. Yield: $49 \%$. Anal. Calc. for $\operatorname{Pr}_{2} \mathrm{C}_{22} \mathrm{H}_{20} \mathrm{O}_{15} \mathrm{~S}_{5}$ : C, 27.3; H, 2.09\%; Found: C, 27.1; H, 2.06\%.

\subsubsection{Synthesis of compound $\left\{\left[\mathrm{Nd}_{2}(2,5-t d c)_{3}(d m s o)_{2}\right] \cdot \mathrm{H}_{2} \mathrm{O}\right\}_{n}$ (3)}

Compound (3) was obtained by applying the same synthetic procedure as described for (1), except that $\mathrm{NdCl}_{3} \cdot 6 \mathrm{H}_{2} \mathrm{O}(50 \mathrm{mg}$, $0.13 \mathrm{mmol}$ ) was used instead of $\mathrm{YCl}_{3} \cdot 6 \mathrm{H}_{2} \mathrm{O}$. The resulting solution was allowed to stand and after six weeks, lilac block crystals were formed. Yield: 47\%. Anal. Calc. for $\mathrm{Nd}_{2} \mathrm{C}_{22} \mathrm{H}_{20} \mathrm{O}_{15} \mathrm{~S}_{5}$ : C, 27.1; $\mathrm{H}$, 2.07\%; Found: C, 26.8; H, 2.04\%.
2.2.4. Synthesis of compound $\left\{\left[\mathrm{Sm}_{2}(2,5-\mathrm{tdc})_{3}(\mathrm{dmso})_{2}\right] \cdot \mathrm{H}_{2} \mathrm{O}\right\}_{n}$ (4)

Compound (4) was obtained by applying the same synthetic procedure as described for (1), except that $\mathrm{SmCl}_{3} \cdot 6 \mathrm{H}_{2} \mathrm{O}(50 \mathrm{mg}$, $0.14 \mathrm{mmol}$ ) was used instead of $\mathrm{YCl}_{3} \cdot 6 \mathrm{H}_{2} \mathrm{O}$. The resulting solution was allowed to stand and after six weeks, colorless block crystals were formed. Yield: $49 \%$. Anal. Calc. for $\mathrm{Sm}_{2} \mathrm{C}_{22} \mathrm{H}_{20} \mathrm{O}_{15} \mathrm{~S}_{5}$ : C, 26.8; H, 2.05\%; Found: C, 27.1; H, 2.07\%.

\subsubsection{Synthesis of compound $\left\{\left[\mathrm{Er}_{2}(2,5-t d c)_{3}(d m s \mathrm{O})_{2}\right] \cdot \mathrm{H}_{2} \mathrm{O}\right\}_{n}(\mathbf{5})$}

Compound (5) was obtained by applying the same synthetic procedure as described for (1), except that $\mathrm{ErCl}_{3} \cdot 6 \mathrm{H}_{2} \mathrm{O}(50 \mathrm{mg}$, $0.13 \mathrm{mmol}$ ) was used instead of $\mathrm{YCl}_{3} \cdot 6 \mathrm{H}_{2} \mathrm{O}$. The resulting solution was allowed to stand and after six weeks, light pink block crystals were formed. Yield: $53 \%$. Anal. Calc. for $\mathrm{Er}_{2} \mathrm{C}_{22} \mathrm{H}_{20} \mathrm{O}_{15} \mathrm{~S}_{5}$ : C, 25.9; $\mathrm{H}$, 1.98\%; Found: C, 26.1; H, 2.01\%.

\subsubsection{Synthesis of compound $\left\{\left[\mathrm{Tm}_{2}(2,5-\mathrm{tdc})_{3}(\mathrm{dmso})_{2}\right] \cdot \mathrm{H}_{2} \mathrm{O}\right\}_{n}(\mathbf{6})$}

Compound (6) was obtained by applying the same synthetic procedure as described for (1), except that $\mathrm{TmCl}_{3} \cdot 6 \mathrm{H}_{2} \mathrm{O}(50 \mathrm{mg}$, $0.13 \mathrm{mmol}$ ) was used instead of $\mathrm{YCl}_{3} \cdot 6 \mathrm{H}_{2} \mathrm{O}$. The resulting solution was allowed to stand and after six weeks, colorless block crystals were formed. Yield: $44 \%$. Anal. Calc. for $\mathrm{Tm}_{2} \mathrm{C}_{22} \mathrm{H}_{20} \mathrm{O}_{15} \mathrm{~S}_{5}$ : C, 25.8; H, 1.97\%; Found: C, 25.8; H, 1.96\%.

All the compounds synthesized are stable in air and insoluble in ethanol, acetonitrile, acetone, tetrahydrofuran (THF), but soluble in the $1: 1$ mixture of dimethylformamide $(\mathrm{dmf})$ and dimehylsulfoxide (dmso).

\subsection{3-Single crystal X-ray diffraction}

The single crystal X-ray diffraction data of compound X was collected at room temperature on a Bruker D8 Venture diffractometer equipped with Photon 100 CMOS detector and using MoK $\alpha$ radiation $(0.71073 \AA$ ) from a INCOATEC micro-focus source. Final lattice parameter values and integrated intensities were obtained using SAINT software and a multi-scan absorption correction was applied with SADABS.

X-ray diffraction data collections for compounds (1) and (5) were collected on a Bruker D8 Venture diffractometer equipped with Photon $100 \mathrm{CMOS}$ detector and using MoK $\alpha$ radiation $(0.71073 \AA$ ) from a INCOATEC micro-focus source. Final lattice parameter values and integrated intensities were obtained using SAINT software and a multi-scan absorption correction was applied with SADABS. For the compound (6), the data collection were performed on an Oxford-Diffraction GEMINI diffractometer using Graphite-Enhance Source Mo-K $\alpha$ radiation $(\lambda=0.71073 \AA$ ). Data integration and scaling of the reflections and absorption corrections were carried out with the programs of the Crysalis suite [14]. Final unit cell parameters were based on the fitting of all reflection positions. The structures were solved using direct methods using the Sir-92 program [15]. The positions of the carbon, oxygen, sulfur, and metal atoms of the molecules were unambiguously assigned on consecutive difference Fourier maps. Refinements were performed with SHELXL-2013 [16] based on F2 through a full-matrix least-squares routine. All atoms were refined with anisotropic atomic displacement parameters, except for hydrogen. The latter were located in difference maps and included as fixed contributions according to the riding model [17]. The structures were drawn using the programs ORTEP-3 for Windows [18], MERCURY [19] and Topos 4.0 [20]. Through the latter, the Voronoi-Dirichlet polyhedral volumes and the molecular coordination numbers generated and projected. 


\section{Results and discussion}

3.1. Crystal structures of $\left\{\left[R E_{2}(2,5-t d c)_{3}(d m s o)_{2}\right] \cdot H_{2} O\right\}_{n}\left(R E=Y^{I I I}(\mathbf{1})\right.$, $\operatorname{Er}^{I I I}(\mathbf{5})$ and $\left.\operatorname{Tm}^{I I I}(\mathbf{6})\right)$

Single crystal X-ray diffraction analysis reveals that (1), (5) and (6) are isostructural and crystallize in orthorhombic system with space group Pna2 ${ }_{1}$. Thus, only the crystal structure of $\mathrm{Tm}^{\text {III }}$ complex will be described herein as a representative example. Tables 1 and 2 and S1 (in Supplementary Material) exhibit crystal data and main geometrical parameters of three rare earth complexes. Comparing the listed crystallographic parameters it can be noticed that the three compounds reported here and other three described in the literature [13] are isostructural.

The ORTEP drawing of a structural fragment of $\left\{\left[\mathrm{Tm}_{2}(2,5-t d c)_{3}\right.\right.$ $\left.\left.(\text { dmso })_{2}\right] \cdot\left(\mathrm{H}_{2} \mathrm{O}\right)\right\}_{n}$ with atom numbering schemes is shown in Fig. 1a. The TmMOF has two crystallographically independent lanthanide ions which are surrounded by seven oxygen atoms from three $\mathrm{tdc}^{2-}$ ions and two dmso molecules with average of Tm-O bond distance of 2.284 (7) $\AA$ and O-Tm-O bond angles varying from $71.2(3)^{\circ}$ to $165.6(3)^{\circ}$. The geometry around both $\mathrm{Tm} 1$ and $\mathrm{Tm} 2$ can be described as a distorted capped trigonal prism, in which the dmso has been added to the rectangular face (Fig. 1b).

Each carboxylate group links two adjacent $\mathrm{Tm}^{\text {III }}$ ions in a typical $\mu^{2}$ coordination mode to build one type of binuclear rare earth units $\left[\mathrm{Tm}_{2}\left(\mu^{2}-\mathrm{COO}\right)_{6}\right]$, forming a sinusoidal-like chain known as Secondary Building Unit (SBU) along the $c$ direction (Fig. 2a and b). This sinusoidal-like $\mathrm{Tm}^{\text {III }}$ chain can be viewed as infinite rod-shaped SBUs, which provide effective means to prevent the interpenetration of the final framework. These sinusoidal-like chains are also extended farther with a nearest-neighbor $\mathrm{Tm}^{\mathrm{III}}$... Tm ${ }^{\mathrm{III}}$ distance of $5.2094(6) \AA$ between the two adjacent chain to build a 3D framework along $a$ direction (Fig. 2c).

Several porous MOFs based on rod-shaped SBUs have been reported, in which the rigid bridging ligands provide the walls of the square channels [21-23]. In this study, even the binder being rigid and the sinusoidal SBUs, the network presented itself distorted the diamond-shaped. From the viewpoint of topology, we can consider each $\left[\operatorname{Tm}_{2}\left(\mu^{2}-\mathrm{COO}\right)_{6}\right]$ subunit as a node, and then a 10 -connected net is generated, where each $\left[\operatorname{Tm}_{2}\left(\mu^{2}-\mathrm{COO}\right)_{6}\right]$ node connects to 10 identical $\left[\mathrm{Tm}_{2}\left(\mu^{2}-\mathrm{COO}\right)_{6}\right]$ nodes via ten
Table 2

Selection of the main geometric parameters, bond distance $(\AA)$, bond angles $\left(^{\circ}\right)$ and hydrogen bonds $\left(\AA\right.$ and $\left.{ }^{\circ}\right)$ for compound $\left\{\left[\mathrm{Tm}_{2}(2,5-t d c)_{3}(d m s O)_{2}\right] \cdot \mathrm{H}_{2} \mathrm{O}\right\}_{n}$

\begin{tabular}{|c|c|c|c|}
\hline Tm1-010 & $2.184(6)$ & $\mathrm{Tm} 1-\mathrm{O} 2$ & $2.198(7)$ \\
\hline Tm1-03 & $2.294(7)$ & Tm1-014 & $2.301(7)$ \\
\hline Tm1-07 & $2.310(6)$ & Tm1-06 & $2.327(7)$ \\
\hline Tm1-011 & $2.341(6)$ & Tm2-012 & $2.226(7)$ \\
\hline $\operatorname{Tm} 2-05^{i}$ & $2.230(7)$ & $\mathrm{Tm} 2-\mathrm{O} 4$ & $2.261(7)$ \\
\hline $\operatorname{Tm} 2-013^{i}$ & $2.292(6)$ & $\mathrm{Tm} 2-08$ & $2.305(7)$ \\
\hline Tm2-09 & $2.348(7)$ & $\operatorname{Tm} 2-01^{\mathrm{i}}$ & $2.365(7)$ \\
\hline O10-Tm1-O2 & $158.9(3)$ & O10-Tm1-O3 & $103.6(2)$ \\
\hline $\mathrm{O} 2-\mathrm{Tm} 1-\mathrm{O} 3$ & $81.5(2)$ & 010-Tm1-014 & $112.6(3)$ \\
\hline O2-Tm1-014 & $78.2(3)$ & 03-Tm1-014 & $127.3(3)$ \\
\hline 010-Tm1-07 & $81.0(3)$ & O2-Tm1-07 & $81.1(3)$ \\
\hline O3-Tm1-07 & $72.3(3)$ & 014-Tm1-07 & $148.1(3)$ \\
\hline 010-Tm1-06 & $74.9(3)$ & O2-Tm1-O6 & $126.0(3)$ \\
\hline 03-Tm1-06 & $75.0(2)$ & 014-Tm1-06 & $78.9(3)$ \\
\hline O7-Tm1-06 & $133.0(3)$ & 010-Tm1-011 & $80.1(2)$ \\
\hline $\mathrm{O} 2-\mathrm{Tm} 1-011$ & $85.0(2)$ & 03-Tm1-011 & $147.6(2)$ \\
\hline 014-Tm1-011 & $77.6(2)$ & 07-Tm1-011 & $76.7(3)$ \\
\hline 06-Tm1-011 & $135.4(2)$ & $\mathrm{O} 12-\mathrm{Tm} 2-\mathrm{O} 5^{\mathrm{i}}$ & $165.6(3)$ \\
\hline O12-Tm2-04 & $109.7(3)$ & $\mathrm{O} 5^{\mathrm{i}}-\mathrm{Tm} 2-\mathrm{O} 4$ & $77.6(3)$ \\
\hline $012-\operatorname{Tm} 2-013^{i}$ & $105.7(2)$ & $05^{\mathrm{i}}-\mathrm{Tm} 2-013^{\mathrm{i}}$ & $78.3(2)$ \\
\hline $04-\operatorname{Tm} 2-013^{i}$ & $124.8(3)$ & 012-Tm2-08 & $83.0(3)$ \\
\hline $\mathrm{O} 5^{\mathrm{i}}-\mathrm{Tm} 2-08$ & $85.1(3)$ & O4-Tm2-08 & $150.9(3)$ \\
\hline $013^{\mathrm{i}}-\mathrm{Tm} 2-08$ & $73.0(3)$ & 012-Tm2-09 & $83.4(3)$ \\
\hline $\mathrm{O} 5^{\mathrm{i}-\mathrm{Tm} 2-09}$ & $86.1(3)$ & 04-Tm2-09 & $78.4(3)$ \\
\hline $013^{\mathrm{i}}-\mathrm{Tm} 2-09$ & $147.4(3)$ & 08-Tm2-09 & $77.3(3)$ \\
\hline $012-\mathrm{Tm} 2-01^{\mathrm{i}}$ & $71.2(3)$ & $\mathrm{O} 5^{\mathrm{i}}-\mathrm{Tm} 2-01^{\mathrm{i}}$ & $123.0(2)$ \\
\hline $\mathrm{O} 4-\mathrm{Tm} 2-01^{\mathrm{i}}$ & $79.1(3)$ & $013^{\mathrm{i}}-\mathrm{Tm} 2-\mathrm{O} 1^{\mathrm{i}}$ & $73.9(3)$ \\
\hline $\mathrm{O} 8-\mathrm{Tm} 2-01^{\mathrm{i}}$ & $129.9(3)$ & $09-\operatorname{Tm} 2-01^{\mathrm{i}}$ & $137.6(2)$ \\
\hline O15-H15B ‥ 4 & 163 & $015 \cdots 04$ & $3.048(12)$ \\
\hline $\mathrm{C} 4-\mathrm{H} 4 \cdots \mathrm{S} 5^{\mathrm{ii}}$ & 112 & $\mathrm{C} 4 \cdots \mathrm{S} 5^{\mathrm{ii}}$ & $3.315(11)$ \\
\hline $\mathrm{C} 10-\mathrm{H} 10 \cdots \mathrm{O} 11$ & 161 & $\mathrm{C} 10 \ldots 011$ & $3.380(13)$ \\
\hline $\mathrm{C} 21-\mathrm{H} 21 \mathrm{C} \cdots \mathrm{O} 15^{\mathrm{iii}}$ & 142 & $\mathrm{C} 21 \cdots \mathrm{O} 15^{\mathrm{iii}}$ & $3.375(18)$ \\
\hline $\mathrm{C} 22-\mathrm{H} 22 \mathrm{C} \cdots \mathrm{O} 15^{\mathrm{iii}}$ & 145 & $\mathrm{C} 22 \cdots \mathrm{O} 15^{\mathrm{iii}}$ & 3.285 (19) \\
\hline
\end{tabular}

Symmetry codes: (i) $\mathrm{x}-1 / 2,-\mathrm{y}+3 / 2, \mathrm{z}$; (ii) $-\mathrm{x}+1,-\mathrm{y}+2, \mathrm{z}-1 / 2$ and (iii) $\mathrm{x}, \mathrm{y}+1$,

2,5-tdc ${ }^{2-}$ ligands. Topological analysis by the TOPOS program suggests a bct net, uninodal with a $3^{12} 4^{28} 5^{5}$ point symbol (Fig. 2d). To our knowledge, this topology was observed in DUT-69 and two other MOFs, where $\mathrm{Zn}_{6}, \mathrm{Cd}_{4}$, and $\mathrm{Cd}_{3}$ clusters act as 10-connecting node, respectively [24,25]. Besides, others like that of $\mathrm{Co}_{4}$ and $\mathrm{Cd}_{5}$ clusters were also discovered to construct a 10-connected net but with different topology [26].

Table 1

Crystal data, data collection and structure refinement for $\left\{\left[R E_{2}(2,5-t d c)_{3}(d m s o)_{2}\right] \cdot H_{2} O\right\}_{n}\left(R E=Y^{I I I}, E r^{I I I}\right.$ and $\left.T m^{I I I}\right)$ compounds.

\begin{tabular}{|c|c|c|c|}
\hline Compound & $\mathrm{Y}^{\mathrm{III}}$ & $\mathrm{Er}^{\mathrm{III}}$ & $\mathrm{Tm}^{\text {III }}$ \\
\hline Formula & $\mathrm{C}_{22} \mathrm{H}_{20} \mathrm{Y}_{2} \mathrm{O}_{15} \mathrm{~S}_{5}$ & $\mathrm{C}_{22} \mathrm{H}_{20} \mathrm{Er}_{2} \mathrm{O}_{15} \mathrm{~S}_{5}$ & $\mathrm{C}_{22} \mathrm{H}_{20} \mathrm{Tm}_{2} \mathrm{O}_{15} \mathrm{~S}_{5}$ \\
\hline Formula weight/g mol ${ }^{-1}$ & 862.50 & 1019.20 & 1020.54 \\
\hline Temperature/K & $291(2)$ & $291(2)$ & $120.00(10)$ \\
\hline Crystal system & Orthorhombic & Orthorhombic & Orthorhombic \\
\hline Space group & $\mathrm{Pna2}_{1}$ & $\mathrm{Pna}_{1}$ & $\mathrm{Pna}_{1}$ \\
\hline $\mathrm{a} / \AA ̊$ & $17.4393(5)$ & $17.4095(5)$ & $17.2619(3)$ \\
\hline $\mathrm{b} / \AA$ & $10.1483(3)$ & $10.1198(3)$ & $10.0391(2)$ \\
\hline$c / \AA ̊$ & $17.5771(5)$ & $17.5470(4)$ & $17.5996(3)$ \\
\hline$\alpha /^{\circ}$ & 90 & 90 & 90 \\
\hline$\beta / /^{\circ}$ & 90 & 90 & 90 \\
\hline$\gamma /{ }^{\circ}$ & 90 & 90 & 90 \\
\hline $\mathrm{V} / \AA^{3}$ & $3110.78(16)$ & $3091.44(15)$ & $3049.90(10)$ \\
\hline $\mathrm{Z}$ & 4 & 4 & 4 \\
\hline Crystal size/mm & $0.24 \times 0.17 \times 0.16$ & $0.25 \times 0.15 \times 0.11$ & $0.13 \times 0.08 \times 0.02$ \\
\hline $\mathrm{D}_{\text {calc }} / \mathrm{g} \mathrm{cm}^{-3}$ & 1.842 & 2.190 & 2.227 \\
\hline$\mu(\mathrm{Mo} \mathrm{K} \alpha) / \mathrm{cm}^{-1}$ & 4.120 & 5.798 & 14.427 \\
\hline Transmission factors ( $\min / \max )$ & $0.6171 / 0.745$ & $0.6106 / 0.7454$ & $0.920 / 0.993$ \\
\hline Reflections measured/unique & $42,183 / 5684$ & $39,743 / 5660$ & $64,642 / 5355$ \\
\hline Observed reflections & 5163 & 5563 & 5107 \\
\hline $\mathrm{N}^{\circ}$. of parameters refined & 402 & 402 & 399 \\
\hline$R\left[F_{o}>2 \sigma\left(F_{o}\right)\right]$ & 0.037 & 0.0270 & 0.0280 \\
\hline $\mathrm{w} R\left[\mathrm{~F}_{\mathrm{o}} 2>2 \sigma\left(F_{o}\right)^{2}\right]$ & 0.0840 & 0.0672 & 0.0640 \\
\hline $\mathrm{S}$ & 1.080 & 1.166 & 1.050 \\
\hline
\end{tabular}




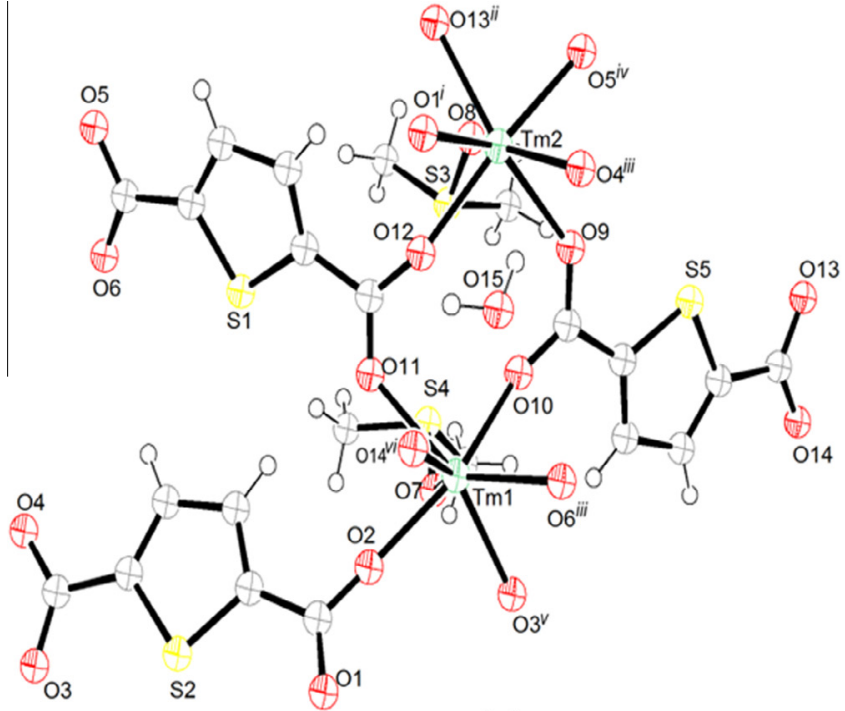

(a)

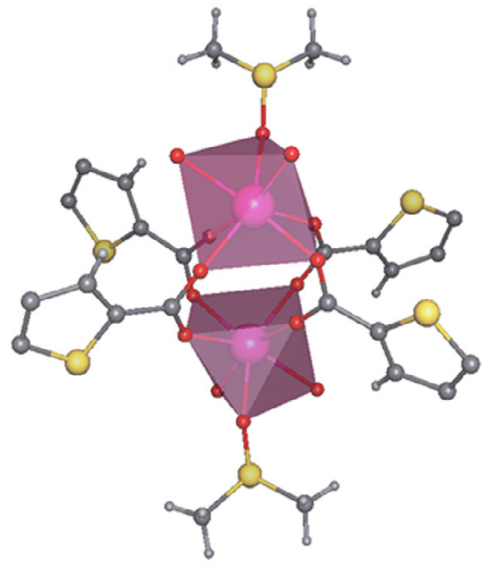

(b)

Fig. 1. (a) Crystal structure of $\left\{\left[\mathrm{Tm}_{2}(2,5-\mathrm{tdc})_{3}(\mathrm{dmso})_{2}\right] \cdot \mathrm{H}_{2} \mathrm{O}\right\}_{n}$. Symmetry codes: $i(-0.5+x, 1.5-y, z) ; i i(1-x, 2-y,-0.5+z) ; i i i(1.5-x,-0.5+y, 0.5+z) ; i v(1-x, 2-y, 0.5+z)$ and vi $(1.5-x,-0.5+y,-0.5+z)$; (b) $\mathrm{Tm}^{\mathrm{III}}$ ions coordination geometry. Polyhedral are $\left[\mathrm{TmO}_{7}\right]$ units, which are connected through $2,5-\mathrm{tdc}^{2-}$ carboxylate groups.

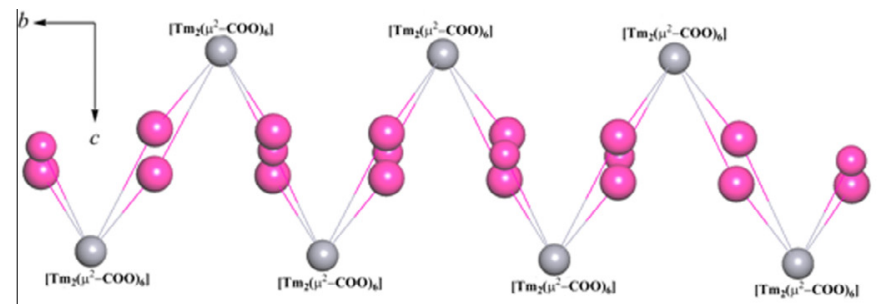

(a)
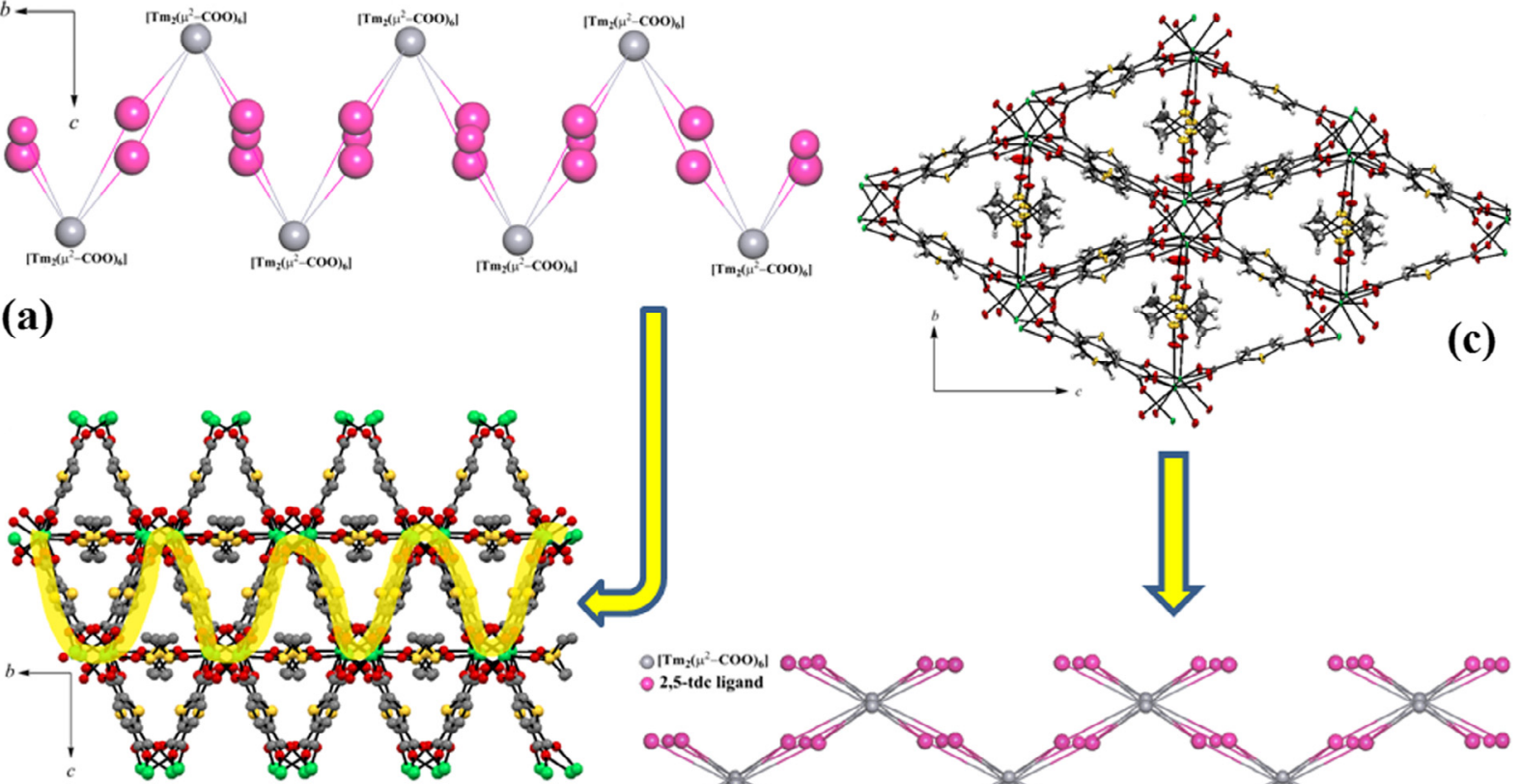

(b)

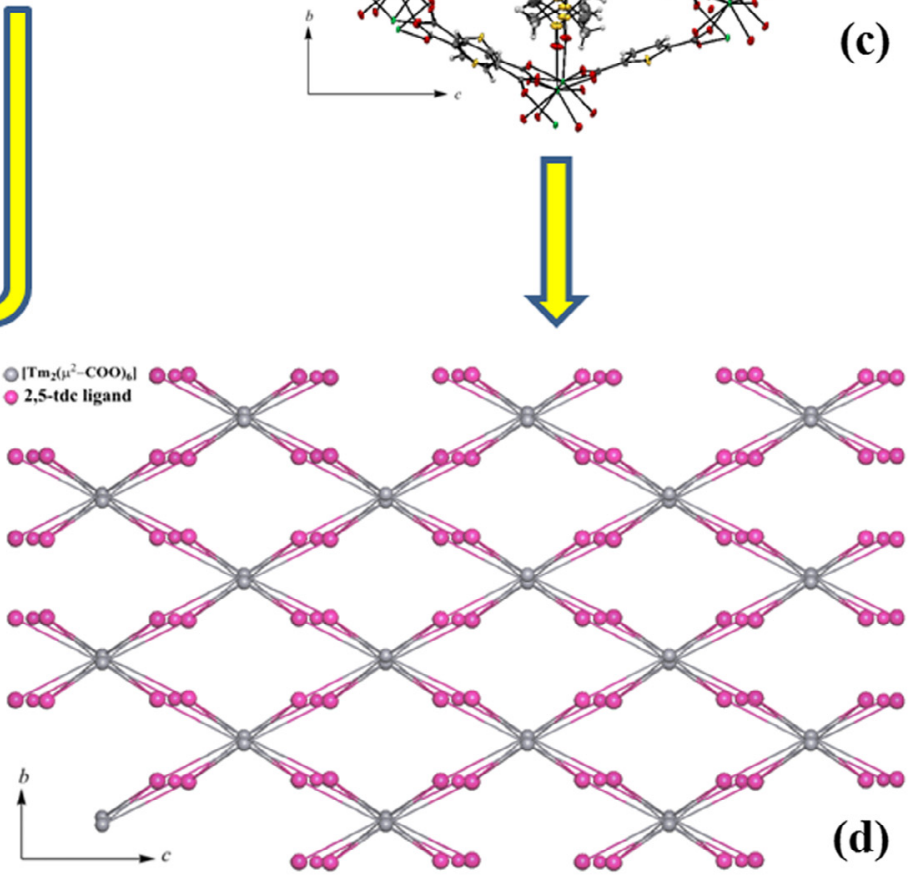

Fig. 2. (a) Structural representation of the simplified sinusoidal-like chain (SBU); (b) View of the sinusoidal SBU in framework along the $b c$ plane. (c) View along bc plane of crystalline framework with inorganic SBUs; (d) A schematic view of the simplified bct type network topology 10-connected.

Fig. A.1, in Supplementary Material, shows the superposition of the three asymmetric units of the isostructural compounds of this paper. It can be seen that for compounds $\mathrm{Y}^{\mathrm{III}}$ and Er ${ }^{\mathrm{III}}$ they are completely overlapped. The $\mathrm{Tm}^{\mathrm{III}}$ compound is displaced in relation to the other two ca. $0.5 \AA$ A. It has been further hydration water molecule for $\mathrm{Tm}^{\mathrm{III}}$ is in the opposite direction to the other two compounds.

The corner-to-corner separations across the channel are ca. 10.04-10.49 A. Hence, the cavities within the material are of 


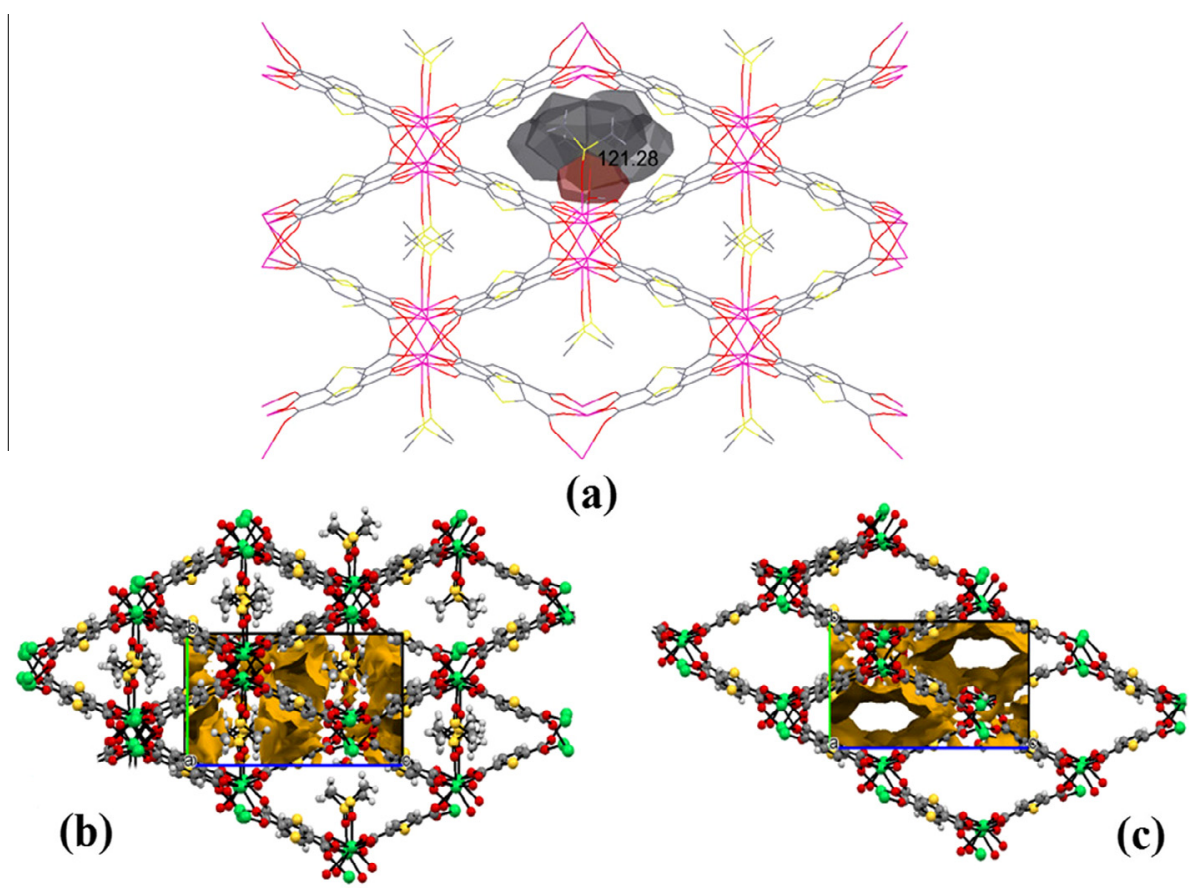

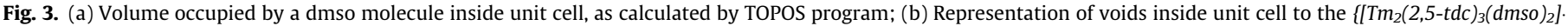
$\left.\mathrm{H}_{2} \mathrm{O}\right\}_{n}$ network and (c) Simulation and calculations of the voids inside unit cell removing the dmso molecules.

considerable capacity; however, these cavities are filled by dmso ligands coordinated to RE $\mathrm{E}^{\mathrm{III}}$ ions. Each molecule of dmso has a volume of $121.28 \AA^{3}$ (calculated by the TOPOS program, Fig. 3a), therefore, these voids are compromised. If we consider the real space of the cavity occupied by dmso molecules, we see that the volume accessible to other host molecules is limited $(11.8 \%$, $344.07 \AA^{3}$ of the $3049.90 \AA^{3}$ of the unit cell total volume). However, if we consider the output of dmso molecules, this accessible volume goes to 29.9\%; $913.09 \AA^{3}$ (as calculated using the program PLATON and MERCURY and shown in Fig. $3 \mathrm{~b}$ and $\mathrm{c}$ ). This result agrees with the volume occupied by each dmso molecule; $121.28 \AA^{3}$ multiplied by the number of dmso molecules in the unit cell (eight); giving a approximate value of $970.24 \AA^{3}$, taking into consideration that each unit cell comprises approximately two cavity and also that each cavity has four molecules of dmso. Thus, the small volume inside unit cell is incapable of host other solvent molecules and gas molecules being necessary to remove the dmso molecules to generate voids favorable to gas adsorption.

The literature reports similar REMOFs containing 2,5- $\mathrm{tdc}^{2-}$ anion [11-13,27-34], with these species being highly crystalline, allowing the structural determination through single crystal $\mathrm{X}$-ray diffraction analysis. However, in the present case, the crystallization process for the $\left\{\left[\mathrm{Pr}_{2}(2,5-t d c)_{3}(d m s O)_{2}\right] \cdot \mathrm{H}_{2} \mathrm{O}\right\}_{n}$ (2), $\left\{\left[\mathrm{Nd}_{2}(2,5-\mathrm{tdc})_{3}(\mathrm{dmsO})_{2}\right] \cdot \mathrm{H}_{2} \mathrm{O}\right\}_{n} \quad$ (3) and $\left\{\left[\mathrm{Sm}_{2}(2,5-\mathrm{tdc})_{3}(\mathrm{dmsO})_{2}\right]\right.$. $\left.\mathrm{H}_{2} \mathrm{O}\right\}_{n}(4)$ compounds resulted in twinned crystals (Fig. 4) and it was not possible to build a crystallographic model for refinement.

For this reason, polycrystalline X-ray diffraction patterns (PXRD) at room temperature were obtained for all the REMOFs. From PXRD patterns exhibited in Fig. A.2 (in Supplementary Material), high crystallinity can be noticed for the all complexes. These data show that complexes (1), (2), (5) and (6) are isomorphous, while compounds (3) and (4) patterns, presents two peaks $\left(9.66^{\circ}\right.$ and $19.40^{\circ}$ in (3) and $9.85^{\circ}$ and $19.60^{\circ}$ in (4)) that are absent in the other patterns, suggesting different crystal lattices. Thus, although the proposed compounds formulation is the same, the crystal packings of compounds (3) and (4) are not. In addition, the difference in reflection intensities among the PXRD patterns was due to the variation in polycrystalline samples preferred orientation during the experimental data collection.
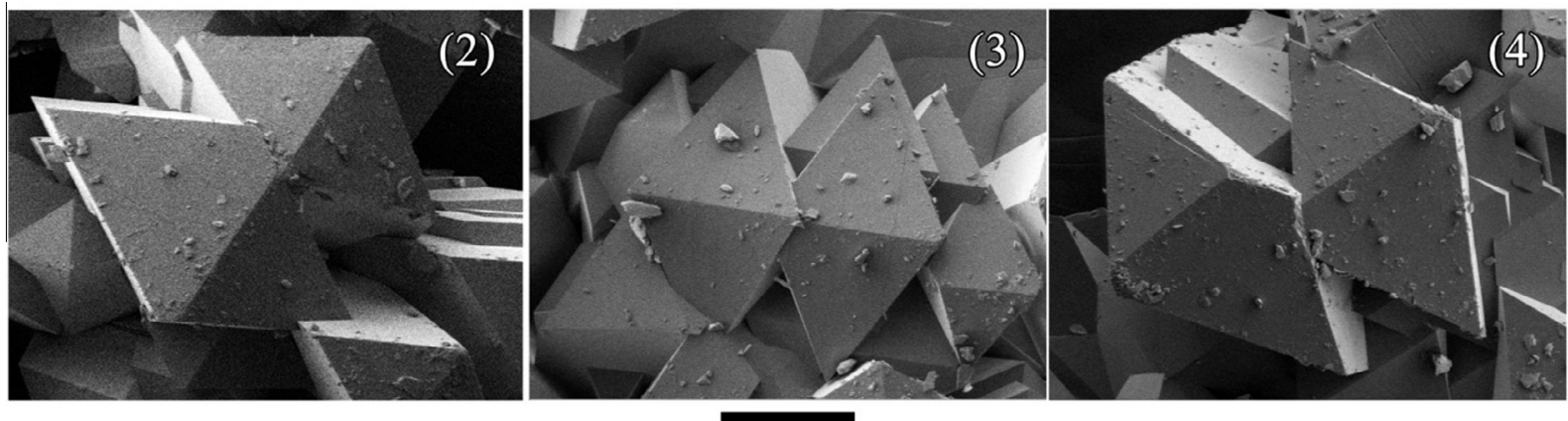

$100 \mu \mathrm{m}$

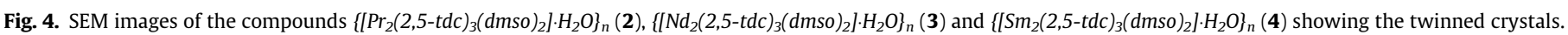




\subsection{Infrared spectroscopy}

The similarity of lanthanide complexes FTIR spectra indicates that these compounds are isostructural as been proved by PXRD method and single crystal X-ray diffraction analysis. The spectra of 2,5- $\mathrm{H}_{2} \mathrm{tdc}, \mathrm{Na}_{2}(2,5-\mathrm{tdc})$ sodium salt and $\left\{\left[R E_{2}(2,5-\mathrm{tdc})_{3}(\mathrm{dmso})_{2}\right]\right.$. $\left.\mathrm{H}_{2} \mathrm{O}\right\}_{n}$ compounds are shown in Figs. A.3 and A.4 of Supporting Material, respectively. In all complexes spectra a broad band centered at $3482 \mathrm{~cm}^{-1}$ may be assigned to $\mathrm{v}(\mathrm{O}-\mathrm{H})$ stretching vibrations, suggesting the presence of water molecules in the structure in accordance to the thermal analysis results discussed below. The $v(\mathrm{C}-\mathrm{H})$ stretching modes of 2,5- $\mathrm{tdc}^{2-}$ thiophene ring and dmso methyl groups appear at 3093 and $2934 \mathrm{~cm}^{-1}$, respectively. The absorption bands at $1271-1292 \mathrm{~cm}^{-1}$ region in the spectrum of $2,5-\mathrm{H}_{2} \mathrm{tdc}$, assigned to stretching vibrations of the non ionized carboxylic groups, are absent in the FTIR spectra of REMOFs, confirming that the ligands are completely ionized, in agreement with the crystal structures. Additionally, the band at $1020 \mathrm{~cm}^{-1}$ may be attributed to the stretching mode $v(S=0)$ indicating the presence coordinated dmso molecules [35]. In this class of carboxylate compounds, the difference $(\Delta v)$ between $v_{\text {asym }}\left(\mathrm{COO}^{-}\right)$and $v_{\text {sym }}\left(\mathrm{COO}^{-}\right)$in comparison to the corresponding values in ionic species is currently employed to propose the carboxylate group coordination mode [36]. The FTIR spectrum of 2,5- tdc $^{2-}$ ligand in ionic form presents strong bands at 1572 and $1382 \mathrm{~cm}^{-1}$, which are attributed to $v_{\text {asym }}\left(\mathrm{COO}^{-}\right)$and $v_{\text {sym }}\left(\mathrm{COO}^{-}\right)$ stretching modes, respectively, providing $\Delta v=190 \mathrm{~cm}^{-1}$. This is an important tool, since rare earth carboxylates usually contain a variety of different coordination modes as a result of their large coordination numbers. For the FTIR spectra of REMOFs, absorption bands are observed at 1571 and $1382 \mathrm{~cm}^{-1}$ assigned to $v_{\text {asym }}\left(\mathrm{COO}^{-}\right)$and $v_{\text {sym }}\left(\mathrm{COO}^{-}\right)$stretching modes, respectively, giving $\Delta v=189 \mathrm{~cm}^{-1}$. Comparing the $\Delta v$ values, one can conclude that the carboxylate groups are coordinated to lanthanide ion in a bridging coordination mode.

\subsection{Thermal analysis}

Properties as volatility and stability, are important for practical applications in luminescent materials. Thus, thermal stabilities of (1)-(6) have been investigated using TGA/DTA techniques (Fig. 5) with polycrystalline samples in the temperature range of 25-800 ${ }^{\circ} \mathrm{C}$ and under a $\mathrm{N}_{2}$ atmosphere. All the complexes exhibit very similar TGA curves, as expected. Therefore, only complex (2) thermal behavior will be discussed in detail as a representative compound for this group. As shown in Fig. 5, at least three well defined weight losses can be noticed in TGA curve for the complex (2). The first endothermic step centered at $125^{\circ} \mathrm{C}$ correspond to the release of one lattice water molecule per formula unit ((1): obsd. 2.04\%, calcd. 2.09\%; (2): obsd. $1.92 \%$, calcd. $1.87 \%$; (3): obsd. $1.87 \%$, calcd. $1.85 \%$; (4): obsd. $1.81 \%$, calcd. $1.83 \%$; (5): obsd.1.74\%, calcd. $1.76 \%$; (6): obsd. $1.73 \%$, calcd. $1.76 \%$ ). Afterwards, two consecutive mass losses accompanied by two endothermic steps (centered at 306 and $350{ }^{\circ} \mathrm{C}$ ) correspond to approximately two coordinated dmso molecules. ((1): obsd.18.39\%, calcd. 18.17\%; (2): obsd. $16.18 \%$, calcd. $16.70 \%$; (3): obsd.16.85\%, calcd. $16.04 \%$; (4): obsd. $15.86 \%$, calcd. 15.84\%; (5): obsd.16.01\%, calcd. 15.37\%; (6): obsd. $15.74 \%$, calcd. $15.32 \%$ ). From $441{ }^{\circ} \mathrm{C}$ to $560{ }^{\circ} \mathrm{C}$ the decomposition of organic moiety takes place with exothermic peaks centered at 455 and $494{ }^{\circ} \mathrm{C}$. At $800{ }^{\circ} \mathrm{C}$, the residual percentage weight is consistent with $\mathrm{Pr}_{2} \mathrm{O}_{3}$ (obsd. $34.20 \%$, calcd. $35.1 \%$ ), $\mathrm{Y}_{2} \mathrm{O}_{3}$ (obsd. $27.10 \%$, calcd. $26.20 \%$ ), $\mathrm{Nd}_{2} \mathrm{O}_{3}$ (obsd. $35.20 \%$, calcd. $34.59 \%$ ), $\mathrm{Sm}_{2} \mathrm{O}_{3}$ (obsd. $36.21 \%$, calcd. $35.41 \%$ ), $\mathrm{Er}_{2} \mathrm{O}_{3}$ (obsd. $38.42 \%$, calcd. $37.55 \%$ ) and $\mathrm{Tm}_{2} \mathrm{O}_{3}$ (obsd. 38.52\%, calcd. 37.75\%) for (2), (1), (3), (4), (5) and (6), respectively. As observed in the TGA curves, there is a very specific temperature range for the release of dmso molecules, allowing generate voids favorable to gas adsorption, as predicted in the crystal structures study. This project is in progress in our research group. Still, it is interesting to note, among all TGA curves, a smaller residual percentage in $\left\{\left[\mathrm{Y}_{2}(2,5-t d c)_{3}(d m s o)_{2}\right] \cdot \mathrm{H}_{2} \mathrm{O}\right\}_{n}(\mathbf{1})$, and this is due to the lower atomic of yttrium element when compared to other rare earth elements.

\subsection{Diffuse reflectance spectra (DR)}

In the absorption spectra of solutions, the solvent effect makes it difficult to study the complexes energy levels. This difficulty can be overcome by studying the diffuse reflectance spectra, allowing the identification of the ligand centered as well as the sharp $4 f-4 f$ transitions. Thus, the diffuse reflectance UV spectra of the investigated REMOFs (Fig. 6) were recorded at room temperature in the region of 230-1300 $\mathrm{nm}$. In the UV region (200-360 nm) of all spectra, a broad absorption band is observed, and can be attributed to electronic transitions from the ground-state level $(\pi) S_{0}$ to the excited level $(\pi *) S_{1}$ of the $2,5-\operatorname{tdc}^{2-}$ anion clearly confirming the ligand coordination in the synthesized compounds. The spectra also displays a set of narrow bands attributed to Laporte-forbidden $4 f-4 f$ transitions of rare earth ions, whose assignments are listed in Table S2 in Supplementary Material.

As expected, the DR spectrum of $\left\{\left[Y_{2}(2,5-t d c)_{3}(d m s o)_{2}\right] \cdot H_{2} O\right\}_{n}(\mathbf{1})$ compound only show absorption the band associated to transition $\mathrm{S}_{0} \rightarrow \mathrm{S}_{1}(\pi, \pi *)$ of the ligand $2,5-\mathrm{tdc}^{2-}$, being very similar to the DR spectrum of $\mathrm{Na}_{2}$ tdc sodium salt (not shown).

\subsection{Photoluminescence studies}

Most of the investigations in the field of luminescent rare earth complexes have been devoted to $\mathrm{Eu}^{\mathrm{III}}$ and $\mathrm{Tb}^{\mathrm{III}}$ compounds, which emit in the visible spectral region and are used as sensors and as luminescent labels in fluoroimmunoassays. Currently much work is being devoted to rare earth compounds emitting in the near infrared (NIR) region for both fundamental reasons and possible applications in some optical fields, especially, telecommunication networks and novel laser materials [37-39]. Taking into account this fact, the photoluminescence properties of $\mathrm{Pr}^{\mathrm{III}}, \mathrm{Nd}^{\mathrm{III}}, \mathrm{Sm}^{\mathrm{III}}$ and $\mathrm{Er}^{\mathrm{III}}$ compounds were studied. All the excitation spectra exhibits a broad band between 250 and $350 \mathrm{~nm}$ which is attributable to the ligand centered $\mathrm{S}_{0} \rightarrow \mathrm{S}_{1}(\pi, \pi *)$ transition of the aromatic moiety. Fig. 7a shows the excitation spectrum of $\left\{\left[\mathrm{Pr}_{2}(2,5-t d c)_{3}\right.\right.$ (dmso $\left.\left.)_{2}\right] \cdot \mathrm{H}_{2} \mathrm{O}\right\}_{n}(2)$ recorded at $77 \mathrm{~K}$ in the $250-600$ range by monitoring the $\mathrm{Pr}^{\mathrm{III}}$ emission at $1032 \mathrm{~nm}$. Three narrow bands are observed which are assigned to $4 f^{2}$ - intraconfigurational transitions from the ground state ${ }^{3} \mathrm{H}_{4}$ to the following excited states of praseodymium ion: ${ }^{3} \mathrm{P}_{2}(448 \mathrm{~nm}),{ }^{1} \mathrm{P}_{1}+{ }^{1} \mathrm{I}_{6}(471 \mathrm{~nm})$ and ${ }^{1} \mathrm{D}_{2}$ $(591 \mathrm{~nm})$. Fig. $7 \mathrm{~b}$ depicts the solid state emission spectra of $\left\{\left[\mathrm{Pr}_{2}(2,5-t d c)_{3}(d m s \mathrm{O})_{2}\right] \cdot \mathrm{H}_{2} \mathrm{O}\right\}_{n}(2)$ recorded at $77 \mathrm{~K}$ upon excitation in the ligand absorption band, at $322 \mathrm{~nm}$. The emission spectrum is composed of the typical $\mathrm{Pr}^{\mathrm{III}}$ emission, corresponding to ${ }^{1} D_{2} \rightarrow{ }^{3} F_{2}(1032 \mathrm{~nm})$ in the NIR region. The solid state excitation (Fig. 7c) and emission (Fig. 7d) spectra of network $\left\{\left[\mathrm{Nd}_{2}(2,5-t d c)_{3}\right.\right.$ $\left.\left.(\text { dmso })_{2}\right] \cdot \mathrm{H}_{2} \mathrm{O}\right\}_{n}$ (3) were studied at nitrogen liquid temperature. Several Laporte-forbidden $4 f-4 f$ transitions in $340-750 \mathrm{~nm}$ range, corresponding to characteristic transitions of $\mathrm{Nd}^{\mathrm{III}}$ ion can also be noticed. These $4 f-4 f$ transitions were assigned to ${ }^{4} \mathrm{I}_{9 / 2} \rightarrow{ }^{4} \mathrm{D}_{5 / 2}$ $(351 \mathrm{~nm}), \quad{ }^{4} \mathrm{I}_{9 / 2} \rightarrow{ }^{2} \mathrm{P}_{1 / 2} \quad(428 \mathrm{~nm}), \quad{ }^{4} \mathrm{I}_{9 / 2} \rightarrow{ }^{4} \mathrm{G}_{11 / 2} \quad(465 \mathrm{~nm})$, ${ }^{4} \mathrm{I}_{9 / 2} \rightarrow{ }^{4} \mathrm{G}_{9 / 2} \quad(509 \mathrm{~nm}), \quad{ }^{4} \mathrm{I}_{9 / 2} \rightarrow{ }^{4} \mathrm{G}_{7 / 2} \quad(523 \mathrm{~nm}), \quad{ }^{4} \mathrm{I}_{9 / 2} \rightarrow{ }^{4} \mathrm{G}_{5 / 2}$ $(580 \mathrm{~nm}), \quad{ }^{4} \mathrm{I}_{9 / 2} \rightarrow{ }^{2} \mathrm{H}_{11 / 2} \quad(624 \mathrm{~nm}), \quad{ }^{4} \mathrm{I}_{9 / 2} \rightarrow{ }^{4} \mathrm{~F}_{9 / 2} \quad(676 \mathrm{~nm})$, ${ }^{4} \mathrm{I}_{9 / 2} \rightarrow{ }^{4} \mathrm{~F}_{7 / 2}+{ }^{4} \mathrm{~S}_{3 / 2}(740 \mathrm{~nm})$. Upon excitation through $2,5-\mathrm{tdc}^{2-}$ ligand singlet state at $312 \mathrm{~nm}$, the emission spectrum of $\left\{\left[\mathrm{Nd}_{2}(2,5-\mathrm{tdc})_{3}(\mathrm{dmsO})_{2}\right] \cdot \mathrm{H}_{2} \mathrm{O}\right\}_{n}$ at $77 \mathrm{~K}$ (Fig. $\left.7 \mathrm{~d}\right)$ show the main characteristic emission lines corresponding to the expected $4 f-4 f$ NIR transitions and correspond to ${ }^{4} \mathrm{~F}_{3 / 2} \rightarrow{ }^{4} \mathrm{I}_{9 / 2}(887 \mathrm{~nm}),{ }^{4} \mathrm{~F}_{3 / 2} \rightarrow{ }^{4} \mathrm{I}_{11 / 2}$ 

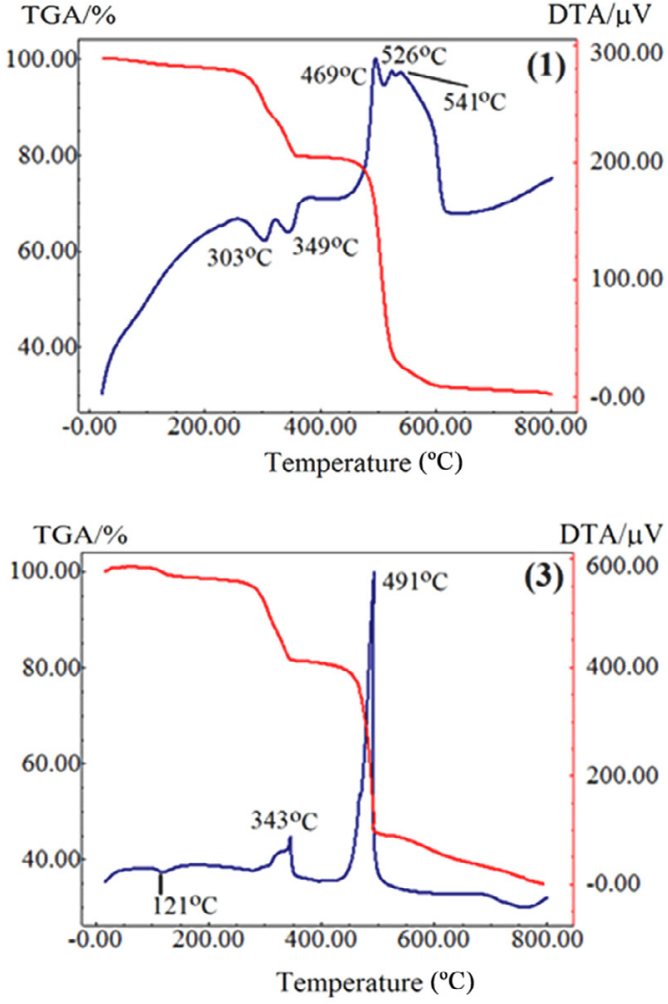

TGA/\%

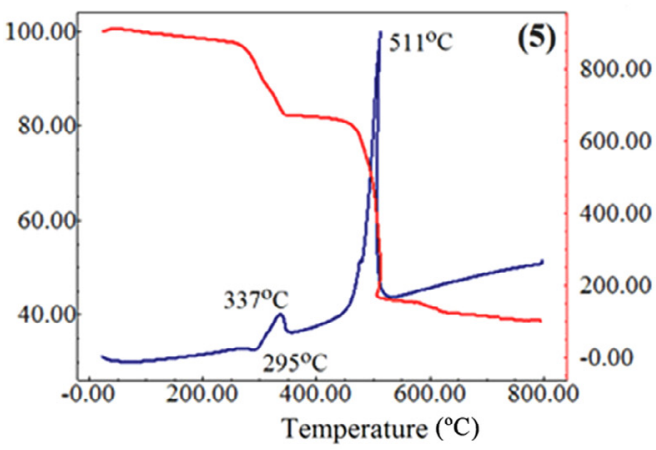

TGA $/ \%$

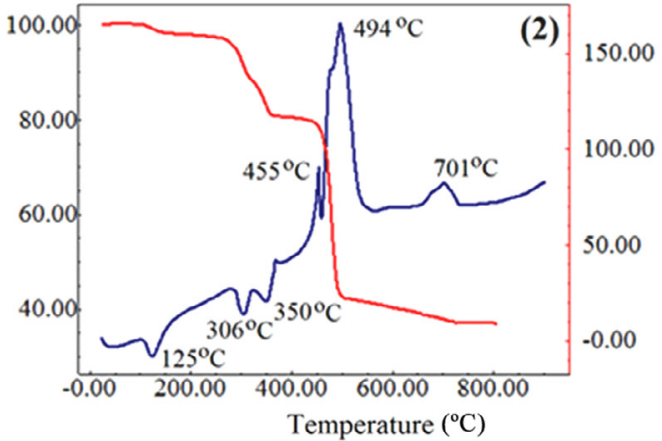

TGA $/ \%$

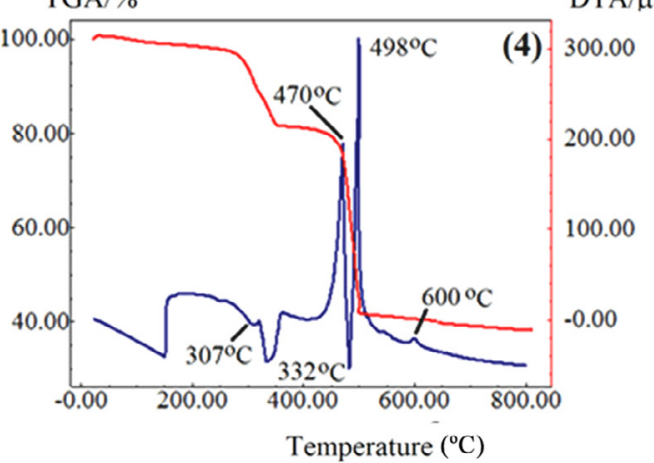

TGA/\%

$\mathrm{DTA} / \mu \mathrm{V}$

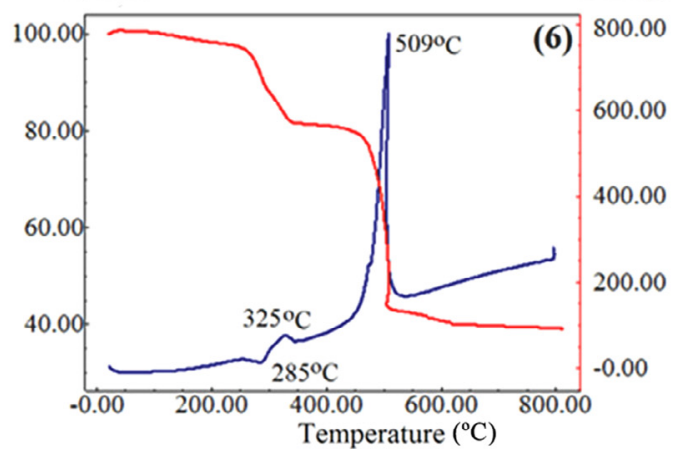

Fig. 5. TGA and DTA curves for the complexes under $\mathrm{N}_{2}$ atmosphere with a heating rate of $10^{\circ} \mathrm{C} / \mathrm{min}$.

$(1053 \mathrm{~nm})$ and ${ }^{4} \mathrm{~F}_{3 / 2} \rightarrow{ }^{4} \mathrm{I}_{13 / 2}(1324 \mathrm{~nm})$ transitions. The normalized excitation spectrum for $\left\{\left[\mathrm{Er}_{2}(2,5-t d c)_{3}(d m s O)_{2}\right] \cdot \mathrm{H}_{2} \mathrm{O}\right\}_{n}$ (5), which was recorded at $77 \mathrm{~K}$, and monitored around the intense ${ }^{4} \mathrm{I}_{13 / 2} \rightarrow{ }^{4} \mathrm{I}_{15 / 2}$ transition of Er ${ }^{\mathrm{III}}$ ion is shown in Fig. 7e. The excitation spectrum of $(\mathbf{5})$ exhibits a series of sharp bands arising of $4 f-4 f$ transitions from the ground state ${ }^{4} \mathrm{I}_{15 / 2}$ level to the ${ }^{2} \mathrm{~K}_{15 / 2}$ (363 nm), ${ }^{4} \mathrm{G}_{11 / 2}(379 \mathrm{~nm}),{ }^{4} \mathrm{G}_{9 / 2}+{ }^{4} \mathrm{~F}_{9 / 2}(407 \mathrm{~nm}),{ }^{4} \mathrm{~F}_{5 / 2}(453 \mathrm{~nm})$, ${ }^{4} \mathrm{~F}_{7 / 2}(488 \mathrm{~nm}),{ }^{2} \mathrm{H}_{11 / 2}(521 \mathrm{~nm})$ and ${ }^{4} \mathrm{~S}_{3 / 2}(547 \mathrm{~nm})$ excited states. However, these transitions are less intense than that of the broad band attributable to the ligand level, which proves that luminescence sensitization via ligand excitation, is more efficient than that direct excitation of the $\mathrm{Er}^{\mathrm{III}}$ ion absorption levels. This coordination network exhibits the characteristic emission band upon excitation in the ligand absorption band, at $315 \mathrm{~nm}$ (Fig. 7f). The emission spectrum is composed of the typical Er ${ }^{\mathrm{III}}$ emission, corresponding to ${ }^{4} \mathrm{I}_{13 / 2} \rightarrow{ }^{4} \mathrm{I}_{15 / 2}(1532 \mathrm{~nm})$ transition. This transition is in the right position of the third telecommunication window $(1.5 \mu \mathrm{m})$ and is currently employed in the telecommunication area [8]. The compound was also excited on the ${ }^{4} \mathrm{I}_{15 / 2} \rightarrow{ }^{4} \mathrm{G}_{11 / 2}$ and ${ }^{4} \mathrm{I}_{15 / 2} \rightarrow{ }^{2} \mathrm{H}_{11 / 2}$ intense transitions (379 and $521 \mathrm{~nm}$, respectively), but no difference in $4 f-4 f$ transitions profile was observed.

The $\mathrm{Sm}^{\mathrm{III}}$ ion has an $4 f^{5}$ electronic configuration, with a odd number of electrons, being classified as an Kramer's ion (electronic levels doubly degenerate by interaction of ligand field for any chemical environment $[40,41])$. Thus, the maximum number of the Stark levels for Kramer ions is $J+1 / 2$ (with ${ }^{2 S+1} L_{J}$ state) for any symmetry lower than cubic [42]. The normalized excitation spectrum for the $\mathrm{Sm}^{\mathrm{III}}$ complex, which was recorded at room temperature, and monitored around the intense ${ }^{4} \mathrm{G}_{5 / 2} \rightarrow{ }^{6} \mathrm{H}_{7 / 2}$ transition for the $\mathrm{Sm}^{\mathrm{III}}$ ion, is shown in Fig. $7 \mathrm{~g}$. In this spectrum, a series of bands arising from $4 f-4 f$ transitions from the ground state ${ }^{6} \mathrm{H}_{7 / 2}$ level to ${ }^{4} \mathrm{H}_{7 / 2}(363 \mathrm{~nm}),{ }^{4} \mathrm{D}_{5 / 2}+{ }^{6} \mathrm{P}_{5 / 2}(373 \mathrm{~nm}),{ }^{6} \mathrm{P}_{7 / 2}(387 \mathrm{~nm})$, ${ }^{4} \mathrm{~L}_{15 / 2}(403 \mathrm{~nm}),{ }^{6} \mathrm{P}_{8 / 2}(418 \mathrm{~nm}),{ }^{6} \mathrm{P}_{5 / 2}+{ }^{4} \mathrm{P}_{5 / 2}(438 \mathrm{~nm})$, and ${ }^{4} \mathrm{G}_{9 / 2}$ $(463 \mathrm{~nm})$ excited states. Upon excitation through the singlet state of the 2,5- $\mathrm{tdc}^{2-}$ ligand, at $310 \mathrm{~nm}$, the emission spectrum of $\left\{\left[\mathrm{Sm}_{2}(2,5-\mathrm{tdc})_{3}(\mathrm{dmsO})_{2}\right] \cdot \mathrm{H}_{2} \mathrm{O}\right\}_{n}(\mathbf{4})$ at room temperature (Fig. $7 \mathrm{~h}$ ) show the main characteristic emission lines of the $\mathrm{Sm}^{\mathrm{III}}$ ion and correspond to the ${ }^{4} \mathrm{G}_{5 / 2} \rightarrow{ }^{6} \mathrm{H}_{5 / 2}(562 \mathrm{~nm}),{ }^{4} \mathrm{G}_{5 / 2} \rightarrow{ }^{6} \mathrm{H}_{7 / 2}(601 \mathrm{~nm})$, 

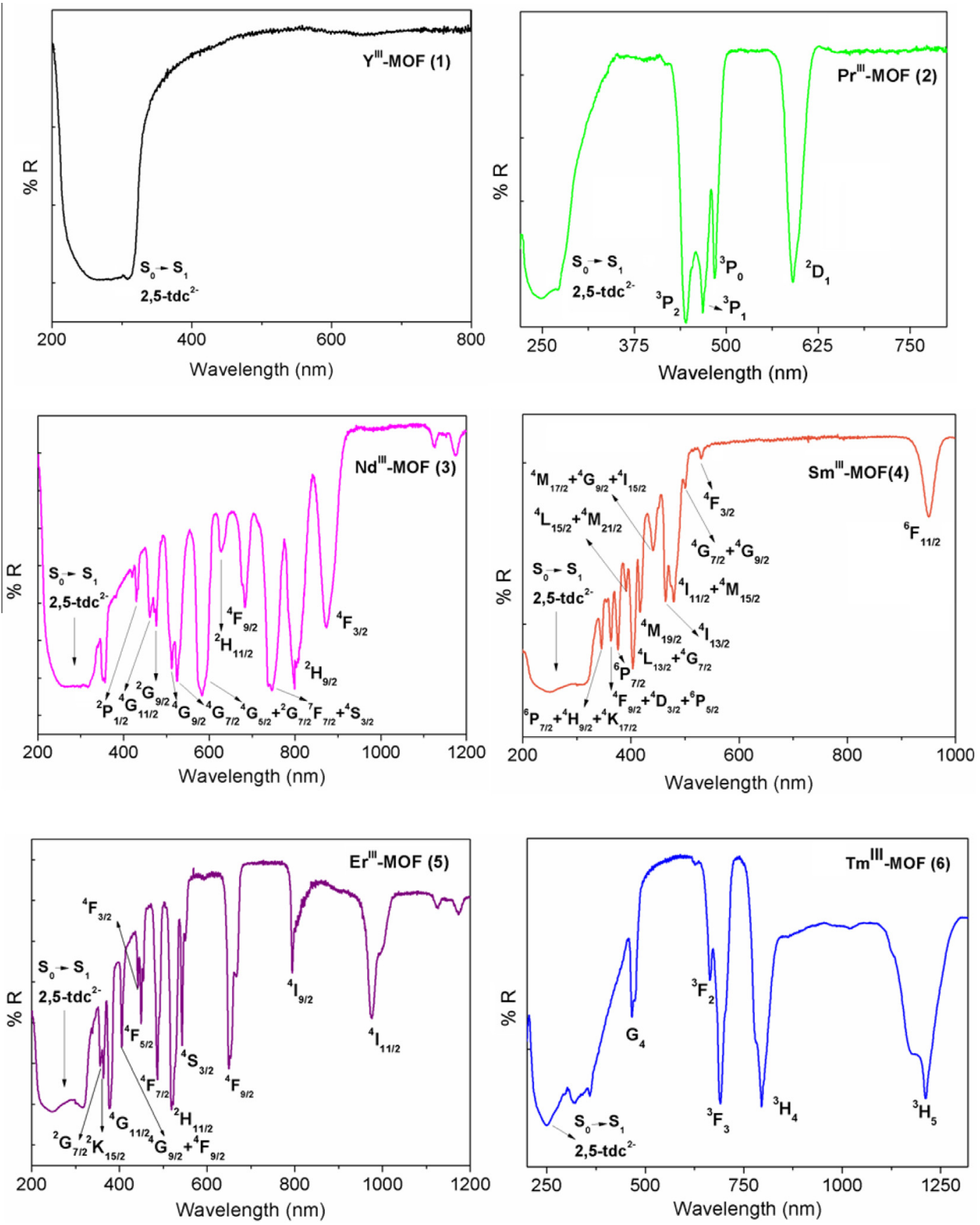

Fig. 6. DR spectra of $\left\{\left[R E_{2}(2,5-t d c)_{3}(d m s o)_{2}\right] \cdot H_{2} O\right\}_{n}$ compounds.

${ }^{4} \mathrm{G}_{5 / 2} \rightarrow{ }^{6} \mathrm{H}_{9 / 2}(646 \mathrm{~nm})$ and ${ }^{4} \mathrm{G}_{5 / 2} \rightarrow{ }^{6} \mathrm{H}_{11 / 2}$ (704 nm). In the $\mathrm{Sm}^{\mathrm{III}}$ compound, the transition ${ }^{4} \mathrm{G}_{5 / 2} \rightarrow{ }^{6} \mathrm{H}_{5 / 2}$ is taken as the reference due to its predominant magnetic dipole character $(\Delta J=0)$. On the other hand, the ${ }^{4} \mathrm{G}_{5 / 2} \rightarrow{ }^{6} \mathrm{H}_{9 / 2}$ transition is magnetic dipole forbidden and electric dipole allowed. Thus, the $\eta_{\mathrm{sm}}$ intensity parameter can be calculated by the equation:

$\eta_{\mathrm{Sm}}=\mathrm{I}\left({ }^{4} \mathrm{G}_{5 / 2} \rightarrow{ }^{6} \mathrm{H}_{9 / 2}\right) / \mathrm{I}\left({ }^{6} \mathrm{G}_{5 / 2} \rightarrow{ }^{6} \mathrm{H}_{5 / 2}\right)$

where I $\left({ }^{4} \mathrm{G}_{5 / 2} \rightarrow{ }^{6} \mathrm{H}_{9 / 2}\right)$ and I $\left({ }^{4} \mathrm{G}_{5 / 2} \rightarrow{ }^{6} \mathrm{H}_{5 / 2}\right)$ are the intensities of ${ }^{4} \mathrm{G}_{5 / 2} \rightarrow{ }^{6} \mathrm{H}_{9 / 2}$ and ${ }^{4} \mathrm{G}_{5 / 2} \rightarrow{ }^{6} \mathrm{H}_{5 / 2}$, respectively [43]. The experimental intensity parameter $\eta_{\mathrm{sm}}$ for the $\left\{\left[\mathrm{Sm}_{2}(2,5-\mathrm{tdc})_{3}(\mathrm{dmsO})_{2}\right] \cdot \mathrm{H}_{2} \mathrm{O}\right\}_{n}(\mathbf{4})$ obtained is approximately 1.82 , indicating that $\mathrm{Sm}^{\mathrm{III}}$ ion is in a low polarizable chemical environment, with the high symmetry.
This small value also confirms the predominance of ${ }^{4} \mathrm{G}_{5 / 2} \rightarrow{ }^{6} \mathrm{H}_{7 / 2}$ transition, corresponding to $59.9 \%$ of emission spectrum.

\subsubsection{Energy transfer mechanism in the REMOFs}

It is important to emphasize that several previous reports of Metal-Organic Frameworks of rare earths with this ligand, discuss briefly the photophysical investigations presenting only the excitation/emission spectra [27-34]. The compounds studied in this work, together with the congeners reported by our group [11-13] presents a more detailed study of energy transfer process. Thus, in order to confirm the possibility of occurrence of antenna effect, the identification of the lowest triplet state of $2,5-\operatorname{tdc}^{2-}$ ligand, was obtained from the emission phosphorescence spectrum 

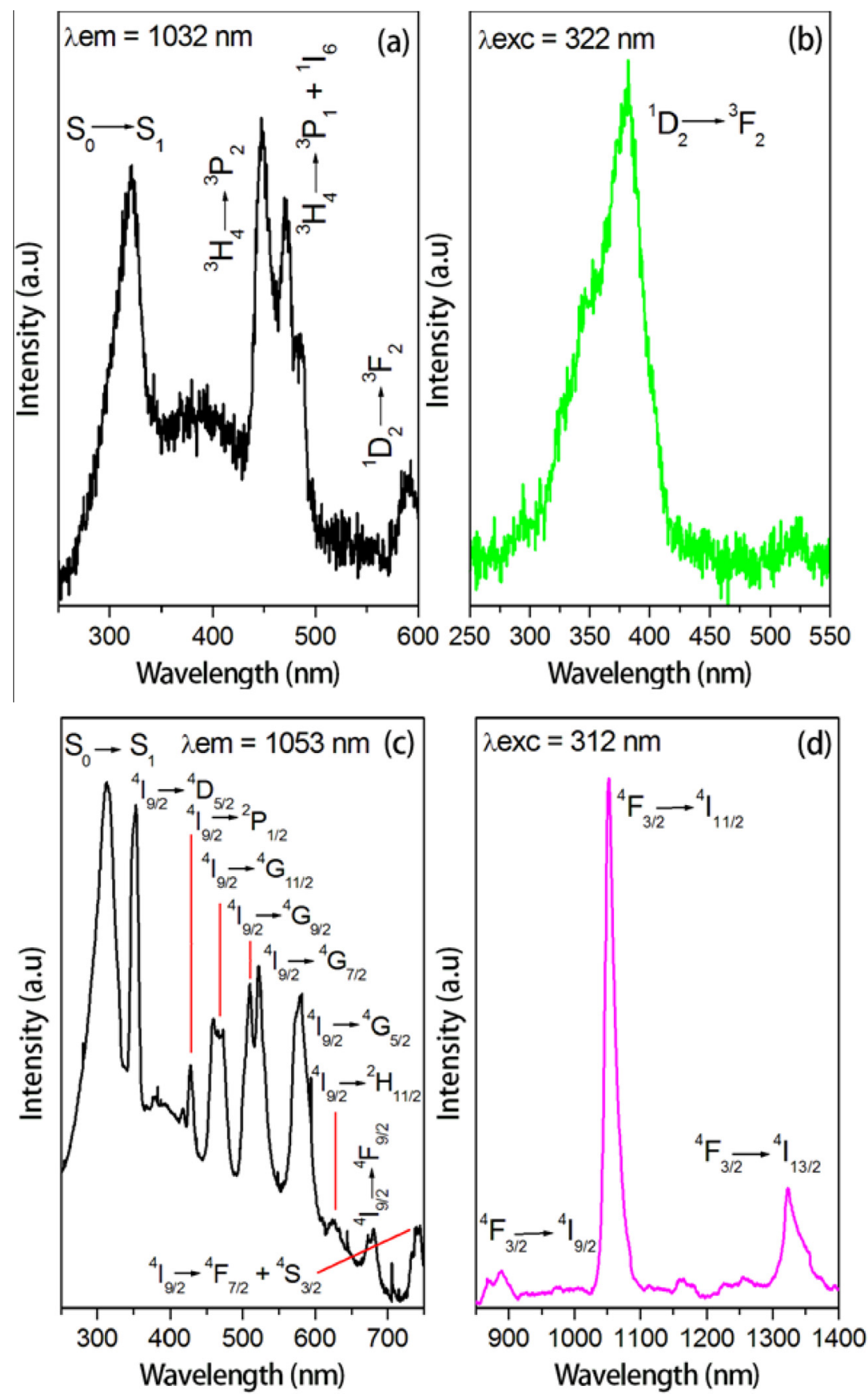

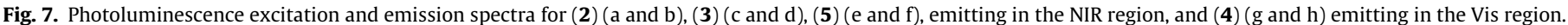
Excitation spectra were obtained at emission maximum, while the emission spectra were obtained upon excitation through 2,5 -tdc ${ }^{2-}$ ligand singlet state.

(Fig. A.5. in Supporting Material) for the $\left\{\left[G d_{2}(2,5-t d c)_{3}(d m s o)_{2}\right]\right.$ $\left.\mathrm{H}_{2} \mathrm{O}\right\}_{n}$ recently reported by our research group [13]. The steadystate phosphorescence spectrum this compound displays two overlapped broad bands that are assigned to the fluorescence $\left(\mathrm{S}_{1} \rightarrow \mathrm{S}_{0}\right)$ (centered at $414 \mathrm{~nm}$ ) and phosphorescence due to the $\mathrm{T}_{1} \rightarrow \mathrm{S}_{0}(\pi, \pi *)$ centered ligand transitions. The time-resolved spectrum, using 0.5 ms delay, enabling determine unequivocally the energy due to the $0-0$ phonon transition for the $\mathrm{Gd}^{\mathrm{III}}$. In this case the fluorescence bands decrease very fast as the flash delay is increased and only the phosphorescence spectrum from the ligands is displayed. Thus, on the basis of the phosphorescence spectra of complex $\left\{\left[\mathrm{Gd}_{2}(2,5-t d c)_{3}(d m s \mathrm{O})_{2}\right] \cdot \mathrm{H}_{2} \mathrm{O}\right\}_{n}$ (Fig. A.5. in
Supporting Material), the triplet energy level $\left(\mathrm{T}_{1}\right)$ of $2,5-\mathrm{tdc}^{2-}$ corresponds to the zero-zero phonon transition and is located at approximately $22,371 \mathrm{~cm}^{-1}(447 \mathrm{~nm})$. The triplet energy level of $2,5-$ tdc $^{2-}$ appears at appreciably higher energy than ${ }^{1} \mathrm{D}_{2}\left(\mathrm{Pr}^{\mathrm{III}}\right)$, ${ }^{4} \mathrm{~F}_{3 / 2}\left(\mathrm{Nd}^{\mathrm{III}}\right),{ }^{4} \mathrm{G}_{5 / 2}\left(\mathrm{Sm}^{\mathrm{III}}\right)$ and ${ }^{4} \mathrm{I}_{13 / 2}\left(\mathrm{Er}^{\mathrm{III}}\right)$ emitting levels, indicating that this ligand can act as an antenna for the photosensitization of trivalent rare earth ions, collecting UV energy and transferring it in a nonradiative process through $T_{1}$ state to excited states of these rare earth ions. There are some levels in the rare earth ions that can efficiently receive energy from the lowest triplet state, for example: ${ }^{3} \mathrm{P}_{1}\left(\sim 22,010 \mathrm{~cm}^{-1}\right)$ in $\mathrm{Pr}^{\mathrm{III}},{ }^{4} \mathrm{G}_{11 / 2}\left(\sim 21,426 \mathrm{~cm}^{-1}\right)$ in $\mathrm{Nd}^{\mathrm{III}}$, ${ }^{4} \mathrm{~F}_{5 / 2}\left(\sim 22,129 \mathrm{~cm}^{-1}\right)$ in $\mathrm{Sm}^{\mathrm{III}}$ and ${ }^{4} \mathrm{~F}_{5 / 2}\left(\sim 22,181 \mathrm{~cm}^{-1}\right)$ in $\mathrm{Er}^{\mathrm{III}}$. 

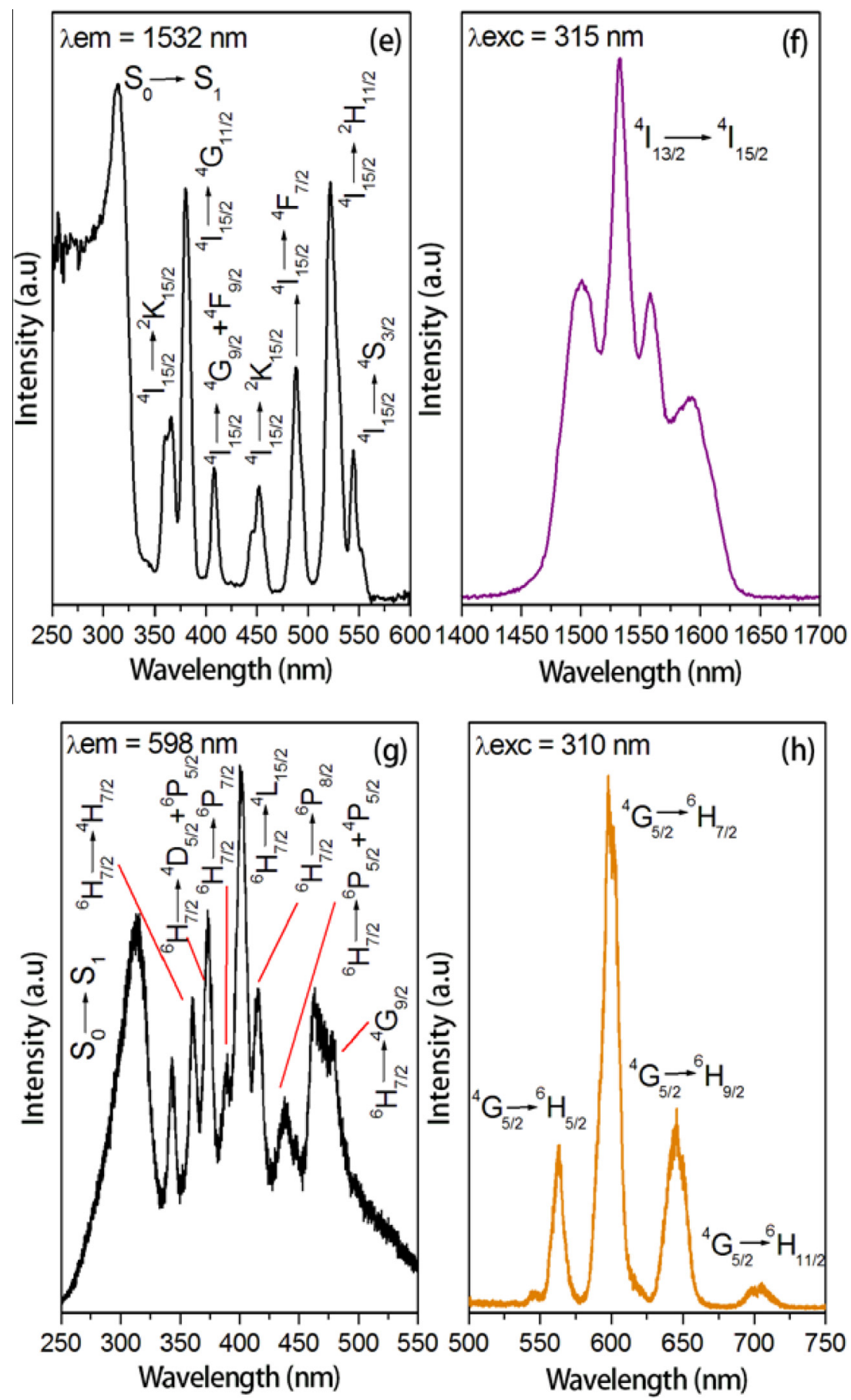

Fig. 7 (continued)

Intense emission, however, is only observed from the ${ }^{1} \mathrm{D}_{2}\left(\mathrm{Pr}^{\mathrm{III}}\right)$, ${ }^{4} \mathrm{~F}_{3 / 2}\left(\mathrm{Nd}^{\mathrm{III}}\right),{ }^{4} \mathrm{G}_{5 / 2}\left(\mathrm{Sm}^{\mathrm{III}}\right)$ and ${ }^{4} \mathrm{I}_{13 / 2}\left(\mathrm{Er}^{\mathrm{III}}\right)$ emitting levels in these REMOFs. The reason for this is the close proximity of these excited states to each other, which causes electrons from the higher states to rapidly relax to the emitting levels, ending with a radiative transition to the ground state. One of factors that governs the luminescence efficiency of rare earth complexes is the energy-level match between the ligand triplet states and $\mathrm{RE}^{\mathrm{III}}$ ion ${ }^{(2 S+1)} \mathrm{L}_{\mathrm{J}}$ state. In this context, an efficient ligand-to-metal energy transfer process for $\mathrm{RE}^{\mathrm{III}}$ needs $\Delta \mathrm{E}\left({ }^{3} \pi \pi *-{ }^{(2 \mathrm{~S}+1)} \mathrm{L}_{\mathrm{J}}\right)>2000 \mathrm{~cm}^{-1}$ [44]. In $\left\{\left[\mathrm{Tm}_{2}(2,5-t d c)_{3}\right.\right.$ (dmso $\left.\left.)_{2}\right] \cdot \mathrm{H}_{2} \mathrm{O}\right\}_{n}(\mathbf{6})$, the energy gap $\Delta \mathrm{E}\left({ }^{3} \pi \pi *-{ }^{1} \mathrm{G}_{4}\right)$ is very small $\left(1071 \mathrm{~cm}^{-1}\right)$, promotes $\mathrm{Tm}^{\text {III }}$-ligand back transfer energy and accounts for the unobservable emission in the $\mathrm{Tm}{ }^{\mathrm{III}}$ compound. Also, the energy gap between ${ }^{1} \mathrm{G}_{4}$ and ${ }^{3} \mathrm{~F}_{2}$ excited states in $\mathrm{Tm}^{\mathrm{III}}$ is relatively large $\left(6108 \mathrm{~cm}^{-1}\right)$ disabling the occurrence of relaxations to lower energy levels and consequently emissions from the ${ }^{3} \mathrm{~F}_{4}$ and ${ }^{3} \mathrm{H}_{4}$ levels $[45,46]$. In addition, the presence of dimethylsulfoxide molecules in the complex may also promote the quenching of luminescence by $\mathrm{C}-\mathrm{H}$ oscillators high frequencies vibrations. Although of unobservable emission in the $\mathrm{Tm}^{\mathrm{III}}$ compound, to the best of our knowledge, this is the first example of crystal structure description involving $2,5-\mathrm{tdc}^{2-}$ ligand and $\mathrm{Tm}^{\mathrm{III}}$ ion. A schematic energy level diagram based on the foregoing is presented in the Fig. 8. 


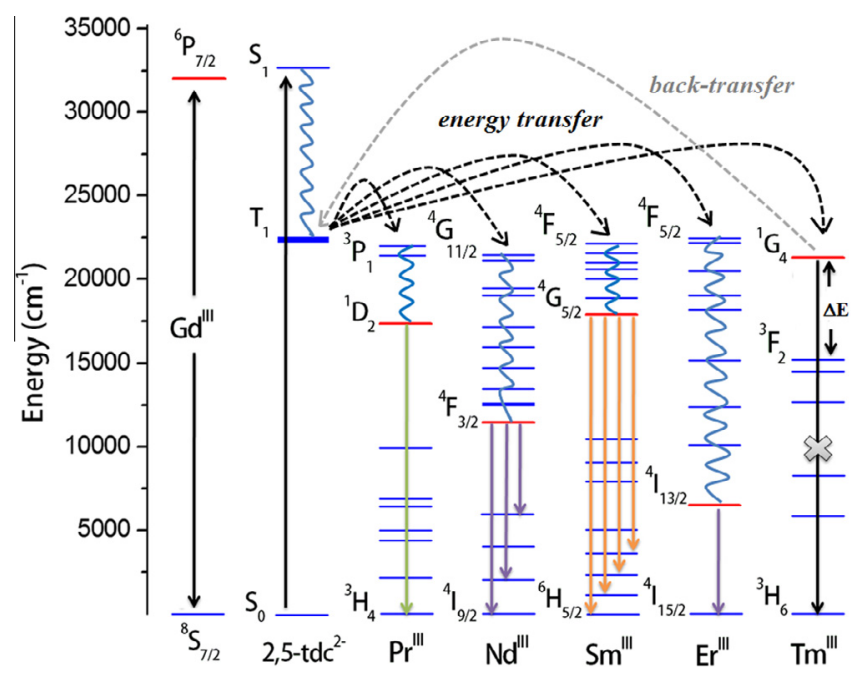

Fig. 8. Energy transfer diagram of $\left\{\left[R E_{2}(2,5-t d c)_{3}(d m s o)_{2}\right] \cdot H_{2} O\right\}_{n}$ complexes representing the mutual positions of the singlet and triplet levels in the 2,5- $\mathrm{tdc}^{2-}$ ligand and the energy levels within the luminescent rare earth complexes. The emitting levels are represented in red. (For interpretation of the references to color in this figure legend, the reader is referred to the web version of this article.)

\section{Conclusions}

In conclusion, we have successfully synthesized six new 3D rare earth-metal organic frameworks of general formula $\left\{\left[\mathrm{RE}_{2}(2,5-\mathrm{tdc})_{3}\right.\right.$ $\left.\left.(\text { dmso })_{2}\right] \cdot \mathrm{H}_{2} \mathrm{O}\right\}_{n}\left(\mathrm{RE}=\mathrm{Y}^{\mathrm{III}}, \mathrm{Pr}^{\mathrm{III}}, \mathrm{Nd}^{\mathrm{III}}, \mathrm{Sm}^{\mathrm{III}}, \mathrm{Er}^{\mathrm{III}}\right.$ and $\mathrm{Tm}^{\mathrm{III}} ; 2,5-\mathrm{tdc}^{2-}=$ 2,5-thiophenedicarboxylate anion; dmso = dimethylsulfoxide) and topology analysis shows a bct net, uninodal with a $3^{12} 4^{28} 5^{5}$ point symbol. The compound of $\mathrm{Sm}^{\mathrm{III}}$ exhibits typical emission in the visible range, while the compounds containing $\mathrm{Pr}^{\mathrm{III}}, \mathrm{Nd}^{\mathrm{III}}$ and $\mathrm{Er}^{\mathrm{III}}$ act as luminescent materials in the NIR region, which is highly desired for biomedical and photonics applications. The data also suggests that $2,5-\mathrm{tdc}^{2-}$ ligand is suitable for the sensitization of luminescence for the $\mathrm{Pr}^{\mathrm{III}}, \mathrm{Nd}^{\mathrm{III}}, \mathrm{Sm}^{\mathrm{III}}$ and $\mathrm{Er}^{\mathrm{III}}$ ions acting as an antenna. Furthermore, such compounds exhibit characteristics which make them potential adsorptive gas material. Research for developing new interesting inorganic-organic hybrid and porous luminescent materials using carboxylate ligands is in progress in our laboratory.

\section{Acknowledgments}

The authors thank the Brazilian agencies CNPq, CAPES, FAPEMIG (CEX-APQ-00808-13) and FAPESP for financial support.

\section{Appendix A. Supplementary data}

Tables with the geometric parameters, bond distance $(\AA)$ and bond angles $\left(^{\circ}\right)$ for $\left\{\left[\mathrm{Er}_{2}(2,5-t d c)_{3}(d m s o)_{2}\right] \cdot \mathrm{H}_{2} \mathrm{O}\right\}_{n}$ and $\left\{\left[\mathrm{Y}_{2}(2,5-t d c)_{3^{-}}\right.\right.$ $\left.\left.(d m s)_{2}\right] \cdot \mathrm{H}_{2} \mathrm{O}\right\}_{n}$ compounds are reported as Supporting Information. CCDC 1459038,1459039 and 1452040 contain the supplementary crystallographic data for the structures reported in this paper. These data can be obtained free of charge via http://www. ccdc.cam.ac.uk/conts/retrieving.html or from the Cambridge Crystallographic Data Centre, 12 Union Road, Cambridge CB2 1 EZ, UK; fax: (+44)1223-336-033; or e-mail: deposit@ccdc.ac.uk.

Supplementary data associated with this article can be found, in the online version, at http://dx.doi.org/10.1016/j.ica.2016.07.008.

\section{References}

[1] C. Biswas, P. Mukherjee, M.G.B. Drew, C.J. Gomez-Garcia, J.M. Clemente-Juan, A. Ghosh, Inorg. Chem. 46 (2007) 10771-10780.

[2] M.H. Alkordi, Y.L. Liu, R.W. Larsen, J.F. Eubank, M. Eddaoudi, J. Am. Chem. Soc. 130 (2008) 12639-12641.

[3] D. Zhao, D.Q. Yuan, H.C. Zhou, Energy Environ. Sci. 1 (2008) 222-235.

[4] B. Chen, C. Liang, J. Yang, D.S. Contreras, Y.L. Clancy, E.B. Lobkovsky, O.M. Yaghi, S. Dai, Angew. Chem., Int. Ed. Engl. 45 (2006) 1390-1393.

[5] N. Sabbatini, M. Guardigli, J.-M. Lehn, Coord. Chem. Rev. 123 (1993) 201-228.

[6] G.F. de Sá, O.L. Malta, C.D. Donega, A.M. Simas, R.L. Longo, P.A. Santa-Cruz, E.F. da Silva, Coord. Chem. Rev. 196 (2000) 165-195.

[7] J.-C.G. Bunzli, S.V. Eliseeva, Chem. Sci. 4 (2013) 1939-1949.

[8] S.V. Eliseeva, J.-C.G. Bunzli, New J. Chem. 35 (2011) 1165-1176.

[9] B. Chen, L. Wang, Y. Xiao, F.R. Froczek, M. Xue, Y. Cui, G. Qian, Angew. Chem., Int. Ed. 48 (2009) 1498-1500.

[10] H.-M. Wang, Y.-Y. Yang, C.-H. Zeng, T.-S. Chu, Y.-M. Zhu, S. Weng, Photochem. Photobiol. Sci. 12 (2013) 1700-1706.

[11] L.F. Marques, C.C. Correa, R.R. da Silva, M.V. dos Santos, S.J.L. Ribeiro, F.C. Machado, Inorg. Chem. Commun. 37 (2013) 66-70.

[12] L.F. Marques, A.A.B. Cantaruti Jr., S.J.L. Ribeiro, F.M. Scaldini, F.C. Machado, Opt. Mater. (Amsterdam. Print) 35 (2013) 2357-2365.

[13] L.F. Marques, C.C. Correa, S.J.L. Ribeiro, M.V. dos Santos, J.D.L. Dutra, R.O. Freire, F.C. Machado, J. Solid State Chem. 227 (2015) 68-78.

[14] CrysAlis ${ }^{\mathrm{PRO}}$, Oxford Diffraction Ltd., Version 1.171.32.4 (Release: 17-11-2008) (13:58:09).

[15] A. Altamore, G. Cascarano, C. Giacovazzo, A. Guagliardi, M.C. Burla, G. Polidori, M. Camalli, J. Appl. Crystallogr. 27 (1994) 435-436.

[16] G.M. Sheldrick, Acta Crystallogr., Sect. A: Found. Adv. 71 (2015) 3-8.

[17] C.K. Johnson, in: F.R. Ahmed (Ed.), ORTEP, Crystallographic Computing, Compenhagen, Denmark, 1969, pp. 217-219.

[18] L.J. Farrugia, ORTEP-3 for Windows - a version of ORTEP-III with a Graphical User Interface (GUI), J. Appl. Crystallogr. 30 (1997) 565.

[19] C.F. Macrae, Mercury: visualization and analysis of crystal structures, J. Appl. Crystallogr. 39 (2006) 453-457.

[20] V.A. Blatov, A.P. Shevchenko, D.M. Proserpio, Cryst. Growth Des. 14 (2014) 3576-3586.

[21] Z.-G. Li, G.-H. Wang, H.-Q. Jia, N.-H. Hu, J.-W. Xu, Cryst. Eng. Commun. 10 (2008) 173-176

[22] S.M. Humphrey, J.S. Chang, S.H. Jhung, J.W. Yoon, P.T. Wood, Angew. Chem., Int. Ed. 46 (2007) 272-275.

[23] J. Ryden, S. Oberg, M. Heggie, M. Rayson, P. Briddon, Microporous Mesoporous Mater. 165 (2013) 205-209.

[24] V. Bon, I. Senkovska, I.A. Baburin, S. Kaskel, Cryst. Growth Des. 13 (2013) 1231 1237.

[25] W.C. Song, Q. Pan, P.C. Song, Q. Zhao, Y.F. Zeng, T.L. Hu, X.H. Bu, Chem. Commun. 46 (2010) 4890-4892.

[26] J. Yang, B. Li, J.F. Ma, Y. Liu, J.P. Zhang, Chem. Commun. 46 (2010) 8383-8385.

[27] W. Huang, D. Wu, P. Zhou, W. Yan, D. Guo, C. Duan, Q. Meng, Cryst. Growth Des. 9 (2009) 1361-1369.

[28] J.-G. Wang, C.-C. Huang, X.-H. Huang, D.-S. Liu, Cryst. Growth Des. 8 (2008) $795-798$.

[29] Y.-G. Sun, B. Jiang, T.-F. Cui, G. Xiong, P.F. Smet, F. Ding, E.-J. Gao, T.-Y. Lv, K.V. den Eeckhout, D. Poelman, F. Verpoort, Dalton Trans. 40 (2011) 11581-11590.

[30] C.M. MacNeill, C.S. Day, S.A. Gamboa, A. Lachgar, R.E. Noftle, J. Chem. Crystallogr. 40 (2010) 222-230.

[31] H.X. He, C.-C. Huang, J.-G. Wang, D.-S. Liu, R.-Q. Sun, Chinese J. Struct. Chem. 28 (11) (2008) 1367-1372.

[32] J. Xu, J. Cheng, W. Su, M. Hong, Cryst. Growth Des. 11 (2011) 2294-2301.

[33] J. Ren, Y. Liu, Z. Chen, G. Xiong, B. Zhao, Sci. China Chem. 55 (2012) 1073-1078.

[34] P.J. Calderone, A.M. Plonka, D. Banerjee, Q.A. Nizami, J.B. Parise, Solid State Sci. 15 (2013) 36-41.

[35] A. Abbasi, E.D. Risberg, L. Eriksson, J. Mink, I. Persson, M. Sandstrom, Y.V. Sidorov, M.Y. Skripkin, A.-S. Ullstrom, Inorg. Chem. 46 (2007) 7731-7741.

[36] G.B. Deacon, R.J. Phillips, Coord. Chem. Rev. 33 (1980) 227-250.

[37] J.K.R. Weber, J.J. Felten, B. Cho, P.C. Nordine, Nature 393 (1998) 769-771.

[38] A. Liu, K. Ueda, Opt. Commun. 132 (1996) 511-518.

[39] H. Zellmer, U. Willamowski, A. Tünnermann, H. Welling, S. Unger, V. Reichel, H, R. Muller, J. Kirchhof, P. Albers, Opt. Lett. 20 (1995) 578-580.

[40] P.S. May, D.H. Metcalf, F.S. Richardson, R.C. Carter, C.E. Miller, R.A. Palmer, J. Lumin. 51 (5) (1992) 249-268.

[41] J.F. Martel, S. Jandl, B. Viana, D. Vivien, J. Phys. Chem. Solids 61 (9) (2000) $1455-1463$.

[42] L. Beaury, J. Holsa, J. Korventausta, J.C. Krupa, R.J. Lamminmaki, P. Porcher, H. Rahiala, P.E. Sailynoja, Acta Phys. Polonica A 90 (1997) 1203-1213.

[43] W.D. Horrocks Jr., M. Albin, Prog. Inorg. Chem. 31 (1983) 1.

[44] M. Latva, H. Takalo, V.-M. Mukkala, C. Matachescu, J.C. Rodriguez-Ubis, J. Kankare, J. Lumin. 75 (1997) 149-169.

[45] S. Shuvaev, V. Utochnikova, L. Marciniak, A. Freidzon, I. Sinev, R.V. Deun, R.O. Freire, Y. Zubavichus, W. Grunert, N. Kuzmina, Dalton Trans. 43 (2014) 3121 3136.

[46] O.A. Serra, E.J. Nassar, P.S. Calefi, I.L.V. Rosa, J. Alloys Compd. 275-277 (1998) $838-840$. 